\title{
Las configuraciones emergentes del consumo. Transformaciones del comercio minorista y restructuración de la centralidad en la región metropolitana de Buenos Aires
}

Lorena Vecslir

CONICET - Universidad de Buenos Aires. Facultad de Filosofía y Letras. Instituto de Geografía "Romualdo Ardissone". Buenos Aires, Argentina.

\section{Florencia Sciutto}

Universidad de Buenos Aires. Facultad de Filosofía y Letras. Instituto de Geografía "Romualdo Ardissone". Buenos Aires, Argentina.

Recibido: 21 de mayo de 2020. Aceptado: 27 de septiembre de 2020.

\begin{abstract}
Resumen
En una región urbana tan compleja como la de Buenos Aires, los espacios de consumo no pueden reducirse a solo dos formatos (shopping vs. calle comercial) o emplazamientos (centro vs. periferia). Este trabajo busca explicar la estructura y transformaciones del comercio minorista en el contexto metropolitano. Específicamente, se orienta a la construcción de cartografías ilustrativas de las múltiples configuraciones que este segmento económico adquiere en los distintos corredores y coronas metropolitanas, más allá de los modelos jerárquicos y del peso de la centralidad tradicional. En base a datos de Google Maps y otras fuentes complementarias, se generan mapas de diversidad e intensidad comercial que muestran una estructuración lineal de esta actividad a lo largo de antiguas rutas y avenidas supramunicipales, y una concentración nodal en torno a las estaciones ferroviarias, con infiltración en las mallas residenciales e industriales preexistentes. Simultáneamente, se identifican algunas tendencias recientes de transformación o revitalización comercial que suman a los centros, corredores y shoppings tradicionales, nuevos productos tales como shoppings de cercanía, polos gastronómicos y operaciones de renovación de centros comerciales "a cielo abierto". Se parte de la base de que la lectura interpretativa de estas configuraciones emergentes puede servir para identificar dinámicas más amplias de reestructuración de la centralidad metropolitana y especificidades de cada contexto que han tendido a ser soslayadas por estudios urbanos enfocados en los efectos territoriales de la globalización.
\end{abstract}

PALABRAS CLAVE: CENTRALIDAD. COMERCIO Y CONSUMO. TRANSFORMACIONES TERRITORIALES. RENOVACIÓN URBANA. REGIÓN METROPOLITANA DE BUENOS AIRES. 


\title{
Emerging configurations of consumption. Transformations of retail trade and restructuring of centrality in the metropolitan region of Buenos Aires
}

\begin{abstract}
In an urban region as complex as it is Buenos Aires, consumption spaces cannot be reduced to only two formats (shopping centers vs. shopping streets) or locations (downtown vs. periphery). This paper seeks to explain the structure and transformations of the retail commerce in the metropolitan context. Specifically, it is oriented towards the construction of illustrative cartographies of the multiple configurations that this economic segment acquires in the different metropolitan corridors and rings, in addition to the hierarchical models and weight of the traditional centrality. Based on data from Google Maps and other complementary sources, maps of diversity and commercial intensity are generated showing a linear structure of this activity along ancient routes and supramunicipal avenues, along with a nodal concentration around railway stations, with infiltration in the pre-existing residential and industrial fabric. Simultaneously, some recent trends of commercial transformation or revitalization have been identified, that join to the centers, corridors and traditional shopping malls, new products such as neighborhood shopping malls, gastronomic centers, and renovation operations of open-air shopping centers. It is assumed that the interpretative lecture of these emerging configurations can serve to identify broader dynamics of the restructuring of metropolitan centrality and specificities of each context that have tended to be avoided by urban studies focused on the territorial effects of globalization.
\end{abstract}

KEYWORDS: CENTRALITY. RETAIL AND CONSUMPTION. TERRITORIAL TRANSFORMATIONS. URBAN RENEWAL. METROPOLITAN REGION OF BUENOS AIRES.

PALAVRAS-CHAVE: CENTRALIDADE. COMÉRCIO E CONSUMO. TRANSFORMAÇÕES TERRITORIAIS. RENOVAÇÃO URBANA. REGIÃO METROPOLITANA DE BUENOS AIRES.

\section{Introducción}

En las últimas tres décadas, a semejanza de otras grandes metrópolis latinoamericanas, la Región Metropolitana de Buenos Aires (RMBA) ${ }^{1}$ sufrió intensas transformaciones socio-territoriales que involucraron cambios en los patrones y espacios de consumo. Junto a la proliferación de urbanizaciones cerradas, condominios y otras opciones residenciales, la emergencia de nuevos "centros de comando"2 y la diversificación de los lugares de trabajo promovidos, a su vez, por el desarrollo de las infraestructuras de comunicación y la reestructuración de los servicios; surgieron alternativas a los primeros formatos de shopping center y se consolidaron sectores comerciales por fuera de las calles y avenidas tradicionales de los centros de antigua formación. ${ }^{3}$

1 La RMBA abarca la Ciudad Autónoma de Buenos Aires (CABA), los 24 municipios circundantes que forman la primera y segunda corona de la aglomeración, también denominados Conurbano Bonaerense (CB), y los 16 municipios de la tercera corona. En conjunto, comprende un área de $19.680 \mathrm{~km}^{2}$ y una población que hacia 2020 se aproxima a los 15 millones habitantes.

2 Zonas de concentración de equipamientos, funciones y actividades vinculadas al comando de la economía regional, nacional y del capitalismo global (Ciccolella, 1999:17).

3 El contexto de crisis sanitaria indujo o aceleró además otras tendencias en curso, como las compras online, la aparición de espacios "a puerta cerrada" para operaciones y distribución logística, una mayor vacancia de locales en shoppings o avenidas tradicionales, y la revalorización del comercio cotidiano barrial, cuyos 
Las configuraciones emergentes del consumo. Transformaciones del...

Los estudios urbanos sobre esta región metropolitana, sin embargo, parecen haber quedado anclados en una mirada dicotómica que contrapone la propagación -tardía pero potente- del "artefacto" emblemático de la globalización, el shopping center, al abandono del espacio público y a la pérdida de vitalidad de los centros o subcentros tradicionales, estructurados en proximidad a las estaciones ferroviarias. En este binomio podemos enmarcar desde los trabajos seminales de jerarquización de centros realizados por la Comisión Nacional Área Metropolitana de Buenos Aires (CONAMBA) en 1995, hasta las más recientes iniciativas de renovación de las centralidades tradicionales bajo el modelo de Centros Comerciales a Cielo Abierto (CCCA), fundamentadas por sus impulsores como respuesta a los embates del shopping center y al "conflicto" del comercio ambulante (Vecslir y Rodríguez, 2018).

Aun reconociendo estas problemáticas y tendencias globales vinculadas a la lógica del consumo masivo y las políticas neoliberales que se despliegan en la RMBA a partir de los años noventa, consideramos que no es posible reducir el rol del comercio minorista y de los espacios del ocio y el consumo a solo dos formatos (shopping vs. calle comercial) o emplazamientos (centro vs. periferia). En una región metropolitana con una compleja estructura socio territorial que, pese a la fuerte caída de las ventas minoristas en el contexto de crisis sanitaria, ${ }^{4}$ mantiene un alto dinamismo del comercio de calle en los centros tradicionales, a lo largo de las principales rutas y avenidas, en las inmediaciones de los intercambiadores de transporte y en los nuevos distritos gastronómicos y de diseño, existen aspectos de la morfología y el comportamiento de la centralidad comercial que permanecen insuficientemente explicados.

Con el fin de profundizar en su abordaje, el presente trabajo busca explicar la estructura y transformación del comercio urbano en los corredores y coronas de la RMBA (Figura 1). ${ }^{5}$ Especialmente, se orienta a la construcción de cartografías ilustrativas de las múltiples configuraciones que adquiere el comercio minorista, más allá del peso que tiene la centralidad histórica y el carácter jerárquico de este segmento en los modelos densimétricos centro-periferia. A partir del procesamiento y cruce de datos provenientes de Google Maps, se generan mapas de diversidad e intensidad comercial que dan cuenta de la estructuración lineal del comercio a lo largo de antiguas rutas y avenidas supramunicipales, la concentración nodal en torno de las estaciones ferroviarias y una infiltración en las mallas residenciales y de pequeña industria existentes. Al mismo tiempo, con base a un relevamiento de notas periodísticas y trabajo de campo, complementado por verificaciones en Google Street View, se identifican algunas tendencias recientes de transformación de la actividad comercial en la RMBA, sus tipologías representativas y patrones de localización.

impactos eran aún incipientes al momento de elaboración de este artículo, pero que sin dudas abren nuevas perspectivas de estudio.

4 Según un informe elaborado por la Confederación Argentina de la Mediana Empresa (CAME) en julio de 2020, las ventas minoristas en el área metropolitana de Buenos Aires cayeron un $36,3 \%$ respecto a igual mes de 2019, mientras continuó ganando mercado el comercio on-line (https://www.redcame.org.ar/ novedades/9818/ventas-minoristas-pymes-resultados-del-mes-de-julio-2020).

5 El área de estudio de este trabajo se corresponde con el Aglomerado Gran Buenos Aires, definido en función de la extensión de la "mancha urbana", abarcando los 24 partidos de la primera y segunda corona de la RMBA, más diez partidos por fuera del CB. 
Las configuraciones emergentes del consumo. Transformaciones del... LORENA VECSLIR, FLORENCIA SCIUTTO

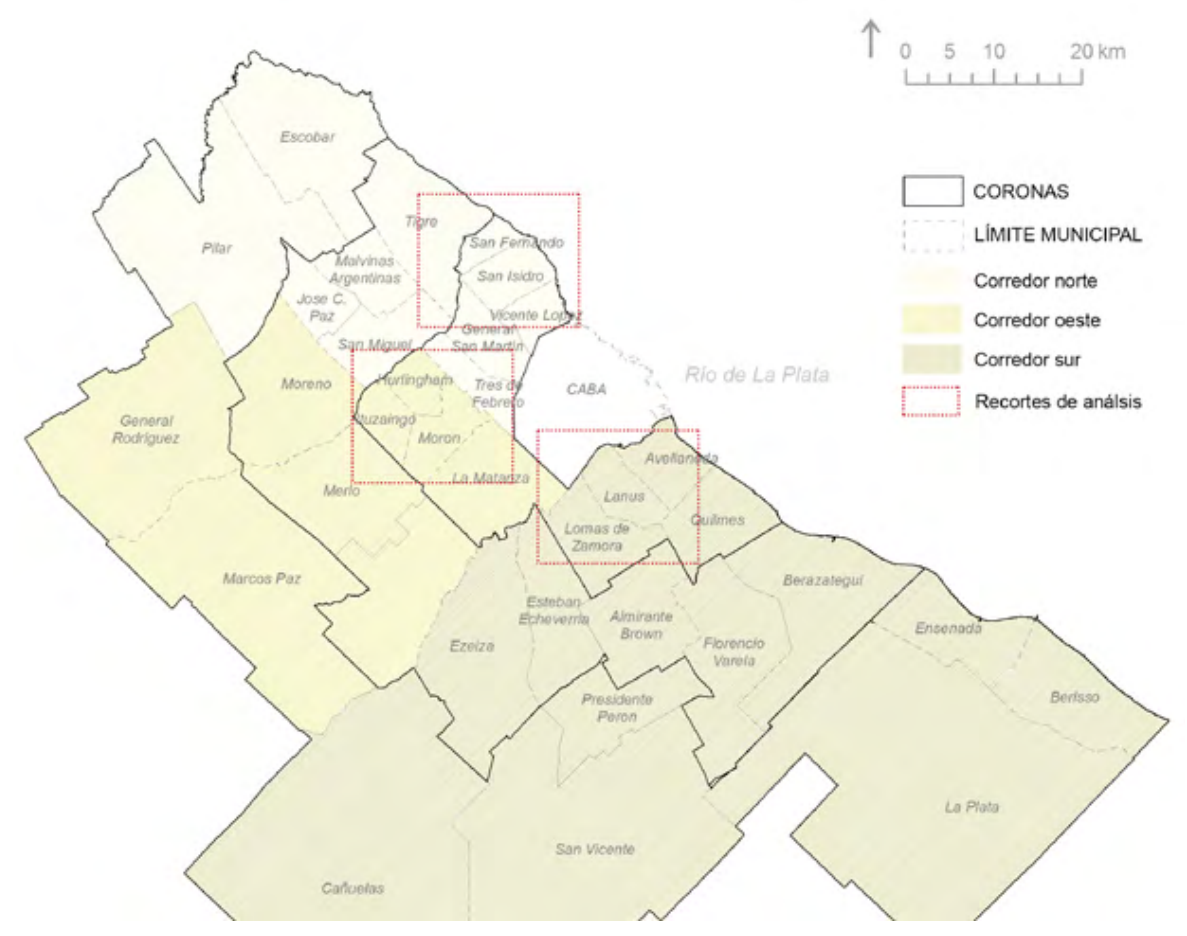

Figura 1. Coronas, corredores y recortes de análisis. Fuente: elaboración propia.

Se parte de la base de que la lectura interpretativa de estas configuraciones de la actividad comercial puede servir para identificar dinámicas más amplias de reestructuración metropolitana, incluidas aquellas de escala barrial, y especificidades de cada contexto que han tendido a ser soslayadas por los estudios urbanos enfocados en los artefactos y efectos territoriales de la globalización. En la misma dirección, se considera que este tipo de estudios puede aportar hacia la diversificación de las políticas urbanas, hoy principalmente canalizadas hacia operaciones de CCCA.

El artículo se estructura en tres apartados. En el primero se mencionan los antecedentes más representativos en el estudio de la centralidad y de la actividad comercial a escala metropolitana en Buenos Aires. En el segundo, se realiza una lectura de la estructura territorial actual del comercio a partir de los datos de Google Maps y se da cuenta de algunas especificidades según las diferentes coronas y corredores metropolitanos. El tercero describe los aspectos tipológicos y las transformaciones recientes de esta actividad, con énfasis en los nuevos formatos del shopping de cercanía, polos gastronómicos y de diseño, y operaciones de renovación de centros tradicionales. Por último, se reflexiona sobre la potencialidad de estos análisis como insumo para la definición de políticas de planeamiento sobre el comercio minorista.

\section{Lecturas metropolitanas de la centralidad comercial}

\section{Estructuras jerárquicas y estructuras continuas}

Los primeros modelos que explican la localización del comercio y los servicios a escala regional (o interurbana) fueron desarrollados y sistematizados por los alemanes Walter 
Las configuraciones emergentes del consumo. Transformaciones del... LORENA VECSLIR, FLORENCIA SCIUTTO

Christaller ([1933] 1966) y August Lösch ([1939] 1957). Partiendo de un supuesto espacio isótropo, servido por un sistema de transporte uniforme, donde la población está distribuida homogéneamente y tiene el mismo poder adquisitivo, Christaller propuso un "modelo de lugares centrales" jerarquizados en función del número de bienes y servicios que éstos proporcionan a residentes y visitantes, lo cual resulta determinante de sus respectivas áreas de influencia (representadas en forma de hexágonos). Aunque de menor reconocimiento, la principal aportación de Lösch sobre este modelo fue la creación de una jerarquía continua, en la que los centros de nivel superior no están obligados a cumplir las funciones de los rangos inferiores, permitiendo la especialización y diferenciación de los mismos.

Entre los antecedentes de modelos desarrollados a escala intraurbana -como la que se aborda en esta investigación-, interesa mencionar, en primer lugar, la "teoría de las actividades terciarias" elaborada por Brian Berry a finales de los años cincuenta. Sobre la base de las mismas premisas de Christaller -acerca de que cada nivel jerárquico contiene las actividades centrales de los niveles inferiores-, esta teoría identificó tres tipos de concentraciones metropolitanas: centros y subcentros jerarquizados, ${ }^{6}$ corredores urbanos y áreas especializadas (Figura 2), insistiendo en una estructura jerárquica escalonada donde existe coincidencia en los umbrales de ciertos grupos de actividades y bienes (Berry, [1958] 1971).

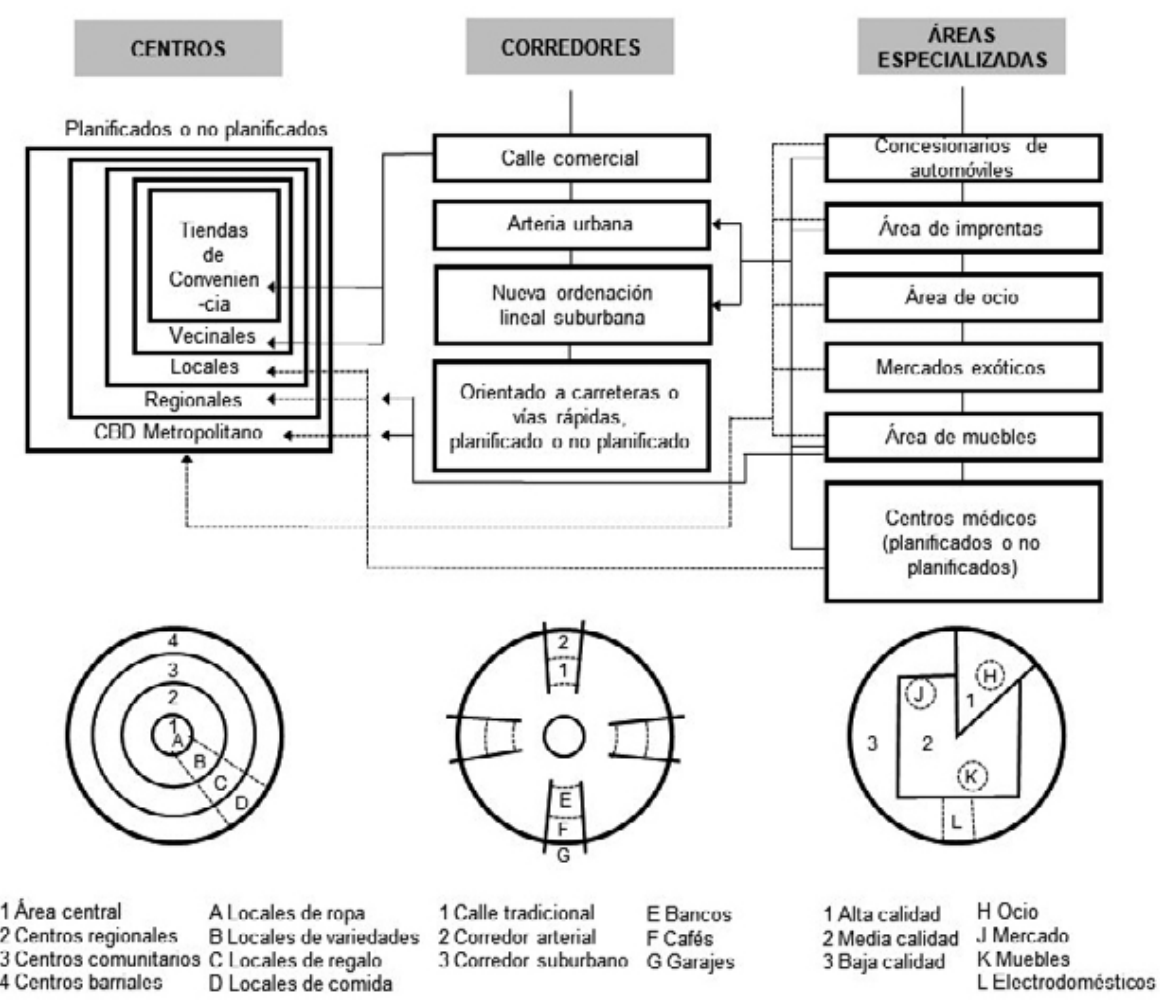

Figura 2. Jerarquía de áreas comerciales según Berry y estructura comercial de un área central. Fuente: elaboración propia a partir de Beavon (1977) y Davies (1972).

6 A su vez, éstos se clasifican en cinco niveles: centros comerciales de uso cotidiano (tiendas de conveniencia), centros vecinales o de barrio, centros locales, centros comerciales regionales y centro metropolitano. 
Las configuraciones emergentes del consumo. Transformaciones del...

Por otra parte, luego de casi 40 años, Keith Beavon recupera la obra de Lösch, demostrando su mejor adaptación al análisis intraurbano, con el desarrollo de una teoría alternativa que avala la noción de jerarquía continua y admite la variación de actividades en los diferentes rangos o niveles jerárquicos (Beavon, [1977] 1981). Esto condujo a evidenciar las múltiples opciones localizativas de una misma actividad en función del umbral de negocios, así como las variaciones introducidas por los niveles de renta, la densidad de población o, incluso, la degradación física y funcional que modifican la teoría de los lugares centrales en áreas urbanas (Moreno Redón, 2011:292).

De esta manera, tuvieron que pasar varias décadas para que se aceptara ampliamente la idea de que las jerarquías del comercio urbano estaban lejos del esquema christalleriano en el sentido de su escalonamiento y regularidad (Kunz, 2003:34) y que, por ejemplo, era necesario estudiar el comportamiento del consumidor y sus motivaciones de desplazamiento, más allá de la cercanía o proximidad del bien de consumo.

En las regiones metropolitanas contemporáneas, de crecimiento fragmentario y baja densidad residencial, con altas tasas de movilidad privada e importantes procesos de polarización social, incluso se cuestiona la propia idea de jerarquía. Actividades comerciales y de servicio que encuentran potenciales consumidores en los flujos de circulación, estructurándose a lo largo de avenidas, carreteras y demás ejes arteriales de escala territorial, desafían la organización jerárquica vertical; así como también lo hacen las áreas o superficies comerciales especializadas, con radios de influencia específicos y complementariedades funcionales, cuya capacidad de atracción se explica también en un cambio de valores culturales y pautas de comportamiento social.

\section{"Desconcentración concentrada” y centralidad comercial en la RMBA}

En este contexto, dentro del campo de los estudios urbanos existe un marcado consenso acerca de la importancia del "comercio de calle", 7 tanto como sector económico con alta capacidad de generación de empleo, como por su aporte al dinamismo y la vitalidad urbana, su rol vertebrador del tejido y de cohesión social (Gehl y Savarre, 2013). La resiliencia de tiendas y distritos comerciales se ha resaltado como cualidad frente a las condiciones cambiantes que desafían el equilibrio del sistema minorista, conservando su viabilidad económica y capacidad de responder a las necesidades de diferentes grupos de consumidores, incluidos los más desfavorecidos (Barata-Salgueiro, 2011). ${ }^{8}$ En un escenario de "explosión de la ciudad”, acompañado de procesos de fragmentación urbana y segregación social, el comercio de proximidad ha sido considerado una actividad clave para promover la ciudad compacta y, por tanto, un valor a preservar, revitalizar y propagar desde las políticas públicas (López de Lucio y Parrilla Gorbea, 1998).

7 Nos referimos a "comercio de calle" en contraposición al comercio alojado en grandes superficies o shop ping centers, lo cual no necesariamente implica una localización central, resultando frecuente la existencia de corredores comerciales en localizaciones periféricas o suburbanas.

8 Incluso, frente al crecimiento del comercio on-line -acelerado por el efecto de la crisis sanitaria- la tienda física sigue siendo, según los expertos en retail, un elemento clave en transformación hacia un espacio experiencial: https://www.lavanguardia.com/economia/20191023/471148089989/comercio-tiendas-digitalcompras-internet.html 
Las configuraciones emergentes del consumo. Transformaciones del...

Con este objetivo, diversos estudios han analizado el empleo y la densidad comercial como variable fundamental en la detección de centros y subcentros metropolitanos (por ejemplo, Truffello e Hidalgo, 2015; Ruiz Lineros y Marmolejo Duarte, 2008). Los resultados de estos trabajos coinciden en señalar la evolución de las respectivas áreas metropolitanas de estudio hacia estructuras cada vez más policéntricas, partiendo de la idea que policentrismo y dispersión son procesos muchas veces simultáneos (GarcíaLópez y Muñiz Olivera, 2007) capaces de dar lugar, utilizando la figura de Dematteis (1998), a una "desconcentración concentrada" de empleos, comercios y servicios.

En las metrópolis latinoamericanas, de acuerdo con De Mattos, este proceso paralelo de expansión urbana y descentralización de servicios colaboró en "la revitalización y modernización de muchos de sus antiguos corredores comerciales, con fuerte impacto en la reorganización urbana" (De Mattos, 2010:97). Así, a las nuevas concentraciones territoriales desarrolladas a partir de shopping centers y centros de negocios, se suman estas centralidades "que resultaron del fortalecimiento, diversificación y ampliación de actividades comerciales tradicionales para el consumo cotidiano local, muchas veces configuradas linealmente a lo largo de ciertas arterias o corredores de antigua tradición comercial" (De Mattos, 2010:97).

En el caso de la RMBA, entre finales de los años noventa e inicios de los 2000, las investigaciones focalizaron su mirada, sobre todo, en los efectos urbanos de los procesos de globalización, entre ellos la "hipermercadización" y la difusión de grandes superficies del ocio y el comercio (Capron, 1996; Guttman, 1997; Ciccolella, 2000). Bajo esta óptica, la centralidad tradicional fue revalorizada en contraposición a la emergencia y acelerado crecimiento del shopping center, ${ }^{9}$ haciendo hincapié en el rol de este último como destino de las grandes inversiones privadas, factor de concentración comercial y competencia con el comercio minorista.

Es así como, en el marco de un relevamiento y análisis realizado por la CONAMBA en 1995, podemos constatar dos tipos de registros con relación a la centralidad metropolitana. Por un lado, elaborada por Artemio Abba, la jerarquización de 115 localidades en tres niveles o categorías, en función de la cantidad y complejidad de equipamiento social e institucional, servicio financiero, comunicación y transporte presentes en cada centro. Por otro, y de manera complementaria, el relevamiento de usos del suelo coordinado por Horacio Bozzano, en el que se identificaban una serie de corredores comerciales, de servicio y, en menor medida, industriales, con continuidad a lo largo de uno o más partidos de la región metropolitana. Estos corredores se estructuraban en vinculación a la red ferroviaria -con subcentros en las estaciones-y a la red de transporte público automotor a lo largo de ejes viales, en su mayoría radiales, "cuya función original de conectividad intra-metropolitana iba siendo desplazada por la propia del corredor, vale decir transporte público y concentración de actividades" (Bozzano, 2000).

Una década más tarde, como parte de la elaboración de los Lineamientos Estratégicos para la RMBA (Dirección Provincial de Ordenamiento Urbano y Territorial,

9 El shopping arribó a Buenos Aires -y a la Argentina- en 1986 con la inauguración del Shopping Sur (cuya actividad cesó en 1997) y terminó de establecerse con las aperturas del Soleil Factory en 1987 y del primer centro comercial regional, el Unicenter, en 1988. Una llegada bastante más tardía que en otras metrópolis latinoamericanas (por ejemplo, en San Pablo donde el primer shopping se inauguró en 1966), pero que enseguida cobró rápido impulso. 
Las configuraciones emergentes del consumo. Transformaciones del...

2005), se actualizaron y volcaron a sistemas de información geográfica los datos relativos a la jerarquía de centros, esta vez basados exclusivamente en la presencia de actividad bancaria, considerando la concentración de actividad financiera minorista como representativa de la existencia de nodos de bienes y servicios centrales (Abba, 2005). Quedaron así definidas para los años 1994 y 2004 tres jerarquías de "centralidades tradicionales" con similar dotación de funciones, sin cuestionar los límites administrativos ni contemplar las posibilidades de competencia o sinergia entre las mismas. Estos "centros tradicionales" fueron además cotejados con las "nuevas centralidades" metropolitanas, directamente asociadas a la presencia de shopping centers, con ámbitos de influencia de escala barrial, urbana y regional (Figura 3).

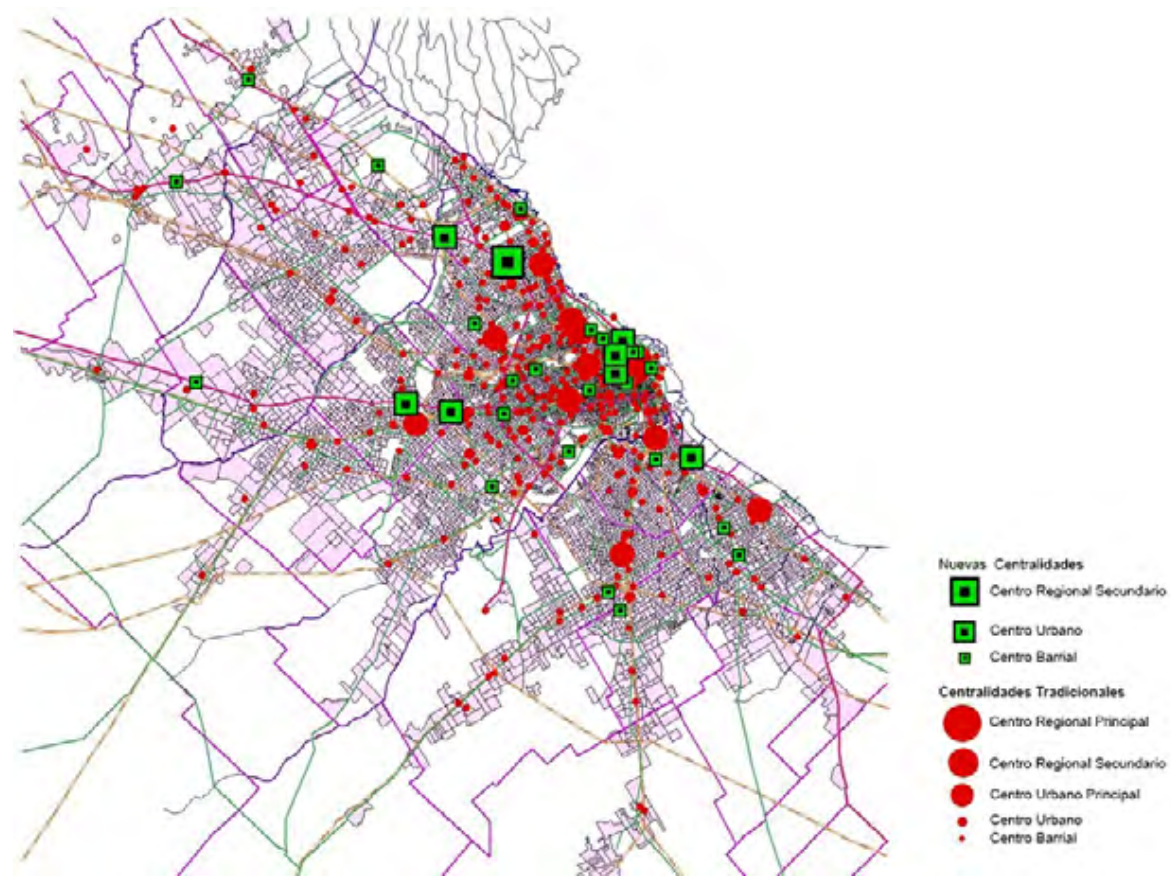

Figura 3. Centros Tradicionales y Nuevas Centralidades, 2004. Fuente: Abba, Laborda, ClHaM, FADU, UBA, 2004.

A partir de los años 2000, la crítica al shopping center y la privatización del espacio público se desplazó progresivamente al estudio del comercio informal ("saladitas" y "manteros") ${ }^{10}$ y de los procesos de gentrificación en los nuevos distritos turísticos, gastronómicos y de diseño (La Boca, Puerto Madero, Palermo), con foco en el desplazamiento de los grupos sociales y tipologías de comercio más vulnerables.

El patrón de localización de los edificios de oficinas premium o clase A+ ha servido, asimismo, para identificar los "centros de comando" que, pese a la alta pervivencia del terciario corporativo en el área central tradicional, desde los años 2000 presentan una

10 Se conoce por mantero a la persona que se dedica a la venta callejera en una plaza o en la vía pública, generalmente sin permiso municipal, poniendo encima de una manta los productos a la venta. Las saladitas, por su parte, son complejos feriales (de menor tamaño que la Feria La Salada, ubicada en el partido de Lomas de Zamora) que basan su funcionamiento en la comercialización de productos de marcas apócrifas. 
Las configuraciones emergentes del consumo. Transformaciones del... LORENA VECSLIR, FLORENCIA SCIUTTO

tendencia creciente de localización en la zona norte de la RMBA (Vecslir y Ciccolella, 2011), con una concentración significativa en torno de dos corredores paralelos a la costa del Río de la Plata: Acceso Norte y Av. del Libertador.

Para el mismo periodo, mientras que en ciertos municipios del norte y noroeste de la región el comercio de calle había quedado relegado frente a los nuevos enclaves del ocio y el consumo, en algunas localidades del eje sur, el relevamiento de los edificios en altura dio cuenta de un proceso de revitalización comercial y verticalización residencial de antiguas centralidades que habían entrado en una fase de estancamiento y deterioro a mediados de la década de 1970 (Ciccolella, Vecslir y Baer, 2015).

No obstante estos análisis y relevamientos, se considera que la revitalización de centros tradicionales y la consolidación de corredores comerciales y de servicio, así como otras formas de concentración comercial, continúan siendo procesos escasamente estudiados, con dimensiones analíticas vacantes más allá de la discusión sobre la ciudad global y los cambios sociales en las prácticas de consumo.

\section{Cartografías del comercio minorista}

\section{La oferta comercial a partir de los datos de Google Maps}

En este marco y a fin de generar un mayor conocimiento de los patrones de localización y características tipológicas del comercio de calle en la RMBA, realizamos un mapeo y análisis de los sistemas de oferta comercial urbana en los municipios de esta región. Se trató de reproducir el tipo de relevamientos efectuados por la CONAMBA, ahora con los recursos on-line disponibles como fuente primaria de información.

En otros contextos, algunos estudios recientes dan cuenta de las posibilidades que ofrecen plataformas como Open Street Maps (Limonta y Paris, 2017) o el cruce entre censos de actividades, datos catastrales y de redes sociales (Sevtsuk, 2010; CarpioPinedo, 2014) para realizar lecturas más detalladas, e incluso evaluar la accesibilidad y el comportamiento social en los entornos comerciales. A nivel local, existen ejemplos como el "Mapa de oportunidades comerciales", construido en 2017 desde ministerio de Modernización en base a tecnologías de big data, que permite conocer los riesgos y oportunidades de abrir un negocio en la Ciudad Autónoma de Buenos Aires (CABA) de acuerdo con información como el número de tiendas del mismo rubro, cantidad de personas que transitan la zona y precios de alquileres de locales. ${ }^{11}$

En nuestro trabajo, se realizó un relevamiento de locales comerciales a partir de los datos provistos por la plataforma Google Maps. ${ }^{12} \mathrm{El}$ relevamiento general llevado a cabo en una primera instancia fue luego sistematizado y reorganizado según categorías más abarcativas, desarrolladas a continuación. El objetivo metodológico

11 La plataforma trabaja con "datos abiertos" provistos por la Agencia Gubernamental de Control, la dirección de Estadísticas y de Planeamiento Urbano, la Administración Gubernamental de Ingresos Públicos, BA Data y la plataforma Properati de análisis del mercado inmobiliario: https://moc.buenosaires.gob.ar/

12 Cabe aclarar que, para optimizar la visualización, la aplicación restringe los campos a la búsqueda de 60 resultados. Por tanto, se efectuó una repetición de las búsquedas por categoría en los "sitios próximos a la vista actual" para maximizar la cantidad de resultados obtenidos. 
Las configuraciones emergentes del consumo. Transformaciones del... LORENA VECSLIR, FLORENCIA SCIUTTO

fue lograr un escaneo continuo y exhaustivo de las acumulaciones comerciales en los partidos de la RMBA, que a su vez permitiera poner en evidencia centralidades comerciales o cúmulos de pequeña escala más allá de su jerarquía o su jurisdicción de pertenencia.

Los datos obtenidos, que incluyen aproximadamente 80 tipos de comercio, fueron luego clasificados en función de tres grandes categorías:

"Espacios de consumo: aquellos destinados a la adquisición de productos. Incluyen locales de indumentaria (ropa, calzado, deporte, lencería, accesorios, joyería); abastecimiento (almacenes, kioscos, farmacias, perfumerías, supermercados express, fiambrerías, casas de comida, panaderías, rotiserías, deliverys, vinotecas, librerías, ferreterías, casas de iluminación, mercerías); hogar y tecnología (electrodomésticos, venta de celulares, casas de iluminación, casas de decoración, bazares), y periféricos (viveros, mueblerías, autopartes, concesionarios, outlets).

»Servicios: locales donde se adquieren prestaciones. Abarcan servicios financieros, aseguradoras y bienes raíces (bancos, cajeros automáticos, mutuales, inmobiliarias); servicios personales (gimnasios, centros de estética, spa, peluquerías, manicuras, depilación); servicios de reparación (zapatero, cerrajería, plomería, modista, tintorería, audio-video, electrodomésticos), y servicios profesionales (abogados, contadores, ópticas, veterinarias).

"Espacios "consumibles": donde se consumen productos y servicios con fines de entretenimiento o socialización. Por ejemplo, locales gastronómicos (bares, cervecerías, restaurants, heladerías), discotecas y salones de fiesta, actividades culturales (centros culturales, teatros, cines, galerías de arte, museos). Incluso ciertos espacios públicos podrían incluirse en esta categoría, "especialmente aquellos que han sido remodelados o diseñados, ya no sólo para cumplir las funciones de un equipamiento urbano, sino para actuar como símbolo y escaparate de un modelo de ciudad" (Benach, 2000:196).

La cartografía obtenida da cuenta de una concentración nodal del comercio en torno a las estaciones ferroviarias, en correspondencia con las localidades cabecera o principales centros urbanos municipales, donde se aglomeran las funciones administrativas, de servicio y comerciales, llegando a superarse los 50 locales por hectárea. La mayor densidad comercial resulta coincidente con dichos centros (Avellaneda, Quilmes, Lanús, Lomas de Zamora, Monte Grande, San Justo, Morón, San Martín, San Miguel, Vicente López, San Isidro, Tigre, etc.) y, en líneas generales, disminuye desde CABA hacia las sucesivas coronas metropolitanas (Figura 4).

Paralelamente, tal como hemos anunciado, destaca la concentración lineal de locales que alternan espacios de consumo y servicio, en torno de vías arteriales radiales y transversales que atraviesan uno o más partidos de la RMBA (rutas provinciales 202, 36,4 ; rutas nacionales 197, 7, 3, entre otras). Se trata de antiguos ejes de movilidad que han perdido su rol de tráfico de paso, y cuya intensidad comercial -a manera de electrocardiograma- aumenta en proximidad a las zonas más densamente pobladas, mutando hacia un tipo de comercio suburbano especializado (muebles, repuestos, 
Las configuraciones emergentes del consumo. Transformaciones del...

LORENA VECSLIR, FLORENCIA SCIUTTO

concesionarios de automóviles, ferreterías, corralones de construcción, viveros, etc.) al alejarse de las mismas.

Por último, pero no menos significativo, existe una subestructura de locales destinados a servicios y comercio cotidiano de escala barrial, que se infiltra en las mallas residenciales e industriales preexistentes.

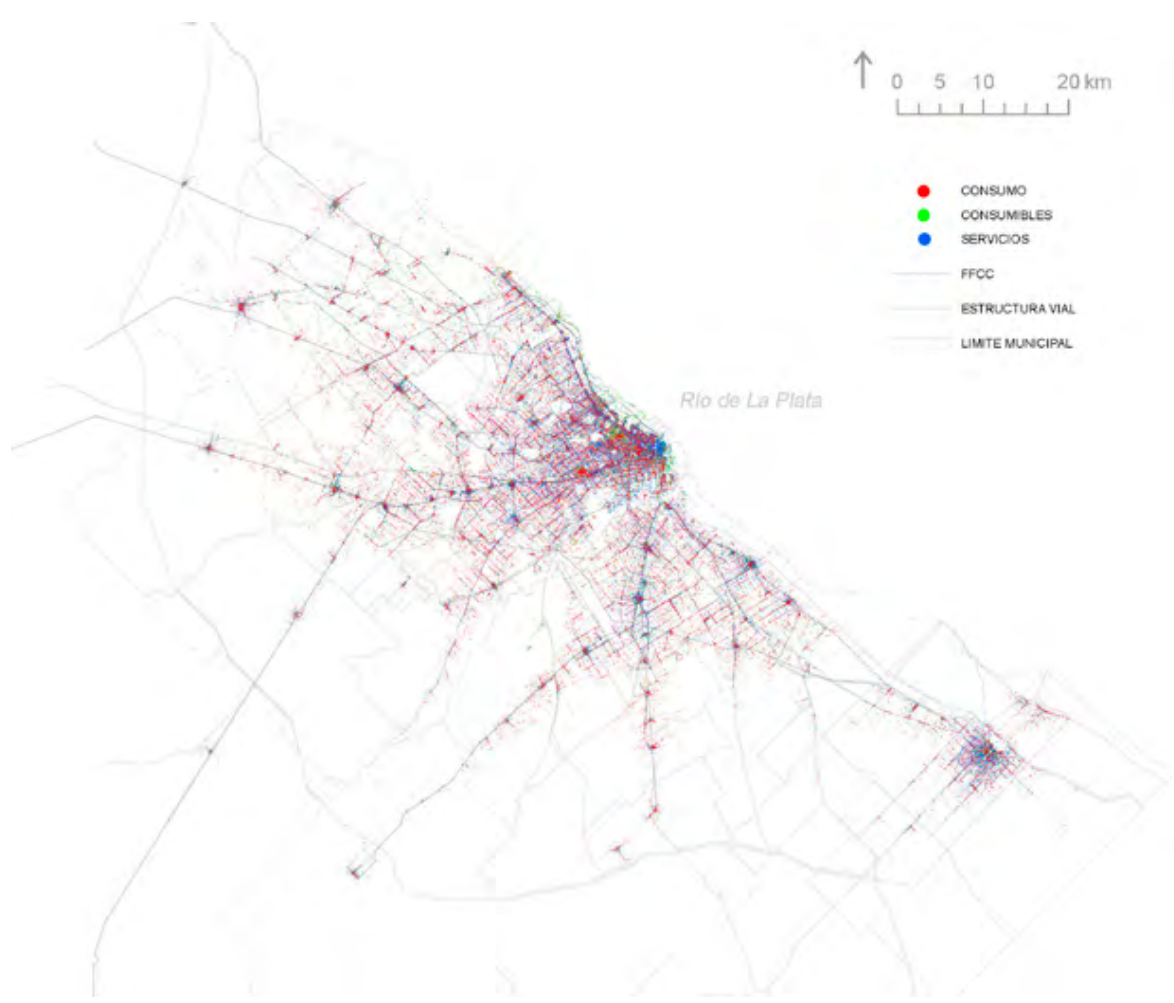

Figura 4. Estructura comercial de la RMBA. Fuente: elaboración propia a partir de datos de Google Maps de 2018.

La predominancia de una estructuración lineal del comercio que caracteriza al mapa anterior se contrapone con el patrón nodal de los "centros tradicionales" jerarquizados en tres niveles (principal, secundario, barrial) de acuerdo a la presencia de actividad bancaria. ${ }^{13}$ También es de carácter nodal la implantación de los 45 shopping centers mayores a $10.000 \mathrm{~m}^{2}$ relevados en la RMBA, 17 situados en la CABA y 28 en la región metropolitana. ${ }^{14}$ La mitad de estos últimos se ubican en la zona norte, próximos a los enlaces viarios del Acceso Norte en sus ramales hacia Tigre, Pilar y Escobar (Figura 5).

13 La fuente de este layer de información es el trabajo realizado por Artemio Abba en 2004 en el marco de los Lineamientos Estratégicos para la RMBA (Abba, 2005).

14 Los centros comerciales menores a $10.000 \mathrm{~m}^{2}$ coinciden con un formato de reciente desarrollo en la RMBA: los shoppings de cercanía. Éstos se analizan en el último apartado del trabajo como nuevos productos comerciales. 
Las configuraciones emergentes del consumo. Transformaciones del...

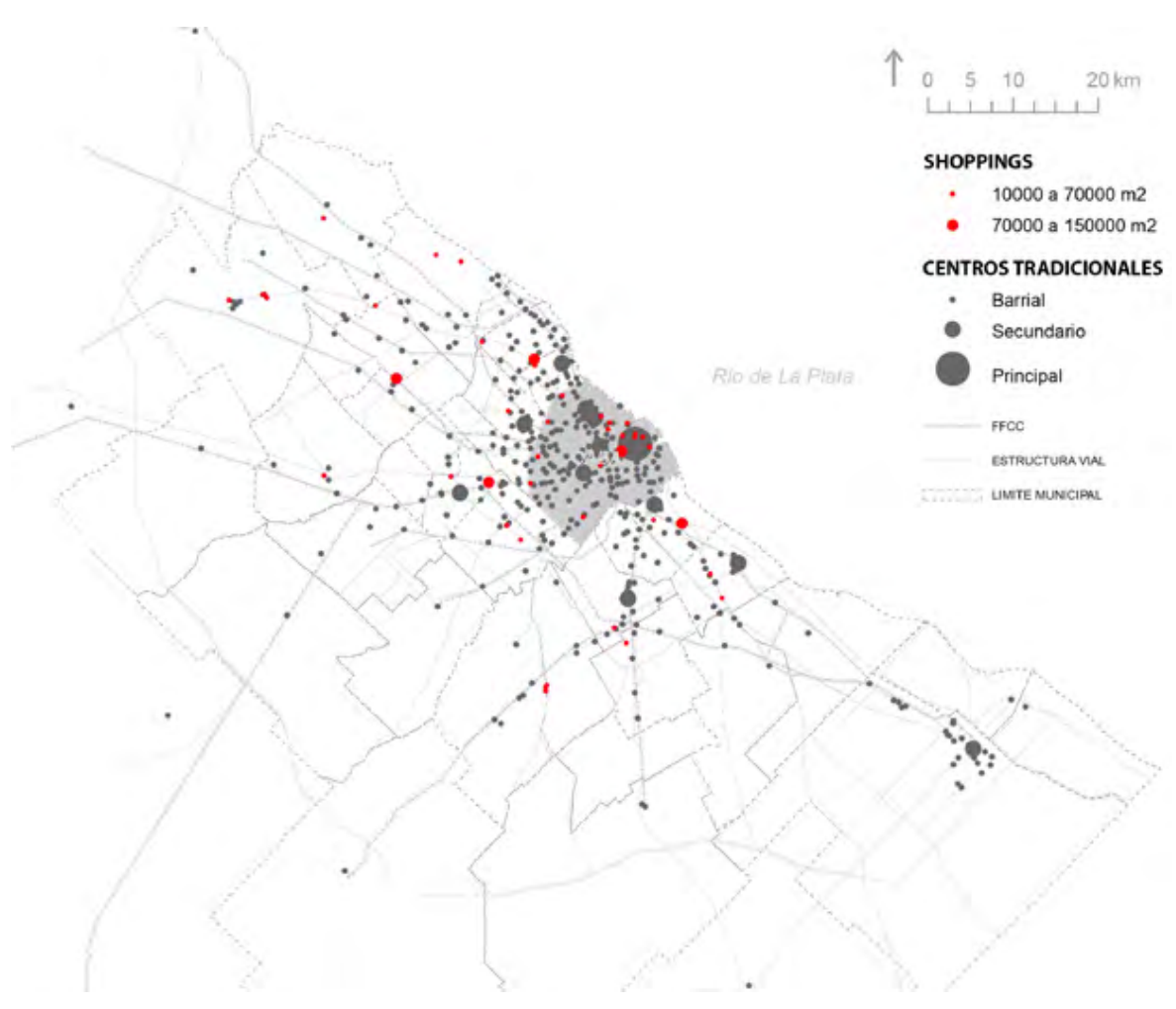

Figura 5. Estructura de centros tradicionales y shopping centers en la RMBA. Fuente: elaboración propia a partir de Lineamientos Estratégicos para la Región Metropolitana de Buenos Aires (Dirección Provincial de Ordenamiento Urbano, 2005) y datos de la Cámara Argentina de Shopping Centers (CASC).

\section{Especificidades de los corredores y coronas metropolitanas}

El recorte de algunos sectores territoriales nos permitió caracterizar de manera particular la estructura comercial según sus distintos contextos de implantación y dar cuenta de ciertos rasgos específicos de acuerdo con las preexistencias, ritmos de crecimiento y tipologías dominantes en los diferentes corredores y coronas metropolitanas. ${ }^{15}$

En el caso de los primeros municipios del corredor norte, por ejemplo, se detectan concentraciones comerciales y de servicio de diverso tamaño, próximas a las estaciones ferroviarias, siendo las más importantes: Martínez, San Isidro, San Fernando y Tigre (Figura 6). La costa del Río de la Plata y el Delta reúnen espacios de ocio y turismo (tren de la Costa, Parque de la Costa, Puerto de Frutos, marinas y clubes náuticos) y, por tanto, aglutinan gran parte de los espacios "consumibles" relevados. En torno a las grandes vías de circulación que estructuran este corredor en dirección paralela al río (Av. Libertador, Av. Maipú y su continuación como Av. Santa Fe y Av. Centenario) se genera una aglomeración lineal casi ininterrumpida a lo largo de $15 \mathrm{~km}$. Asimismo, destacan algunos ejes comerciales, transversales a los anteriores, como las rutas 202 y 197, con mayor intensidad de actividad a la altura de las localidades de Don Torcuato, General Pacheco y El Talar (municipio de Tigre); la ruta 4, especialmente en la localidad de Boulogne Sur Mer (San Isidro), y la Av. Nicolás Avellaneda en la localidad de Virreyes (San Fernando).

15 Para el análisis de la RMBA suelen diferenciarse tres coronas o "cordones" según la distancia de los municipios respecto a CABA, y tres zonas según su orientación (norte, oeste y sur). 
Las configuraciones emergentes del consumo. Transformaciones del...

El conjunto de estos ejes discurre a través de un patchwork de grandes vacíos urbanos (Jockey Club, Hipódromo, Aeropuerto de San Fernando, Campo de Mayo), en alternancia con barrios cerrados, áreas más densamente pobladas y grandes proyectos inmobiliarios cercanos a la ribera de Vicente López y Olivos. Los shoppings más antiguos de la región, Unicenter y Soleil (1988 y 1987), se encuentran en este sector, en el km 17 y en el cruce del Acceso Norte con el Camino del Buen Ayre.

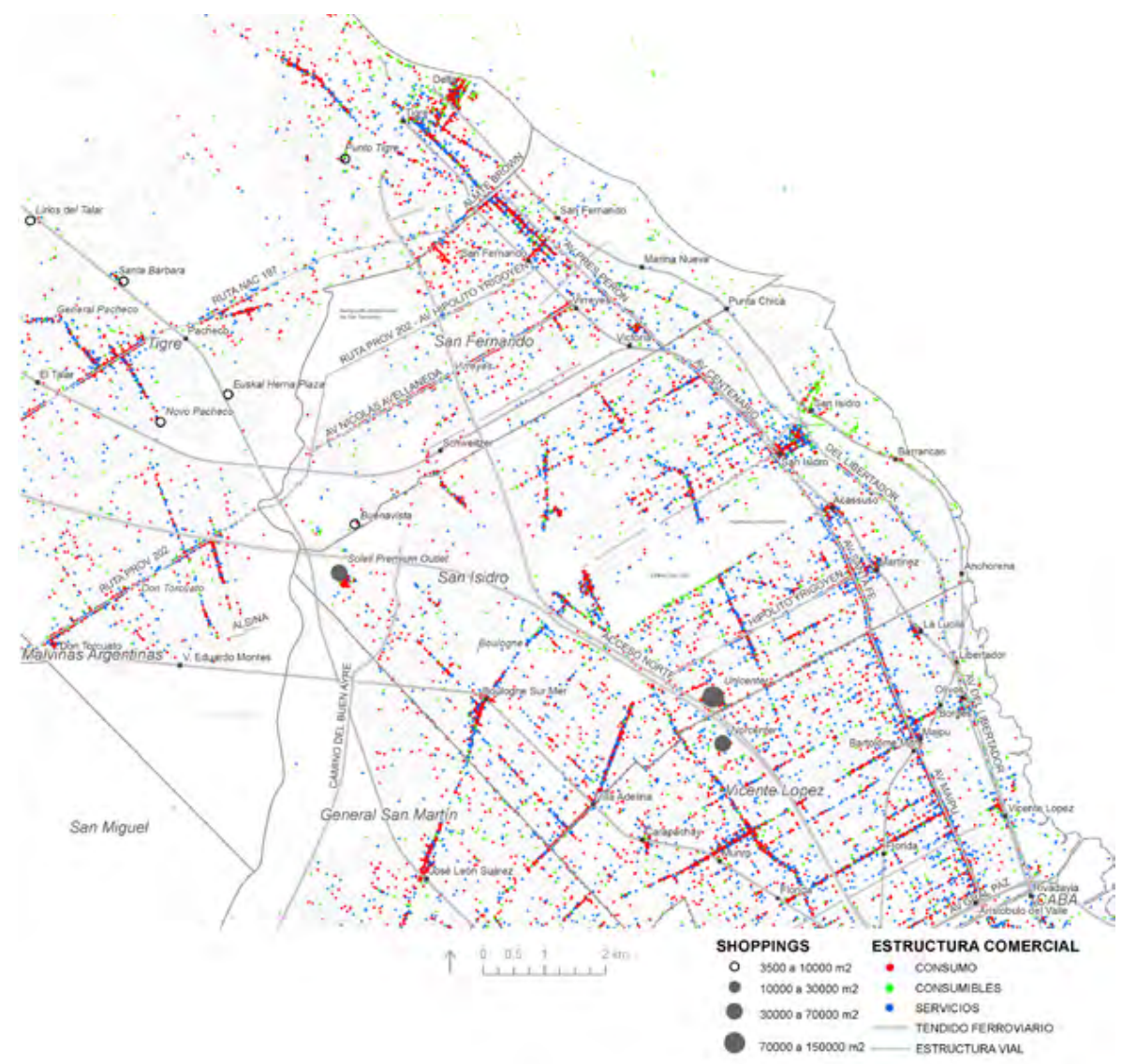

Figura 6. Estructura comercial en los municipios del norte de la RMBA. Fuente: elaboración propia.

Los municipios de la primera corona del eje sur (Avellaneda, Lanús y Lomas de Zamora) muestran algunas especificidades vinculadas a su condición de "corredor urbano sin autopista" (Vecslir et al., 2018) con núcleos de temprana formación de base industrial que, a diferencia de otros ejes metropolitanos (especialmente del Acceso Norte), no han basado sus dinámicas de desarrollo reciente en la accesibilidad provista por una gran arteria viaria (Figura 7). 
Las configuraciones emergentes del consumo. Transformaciones del...

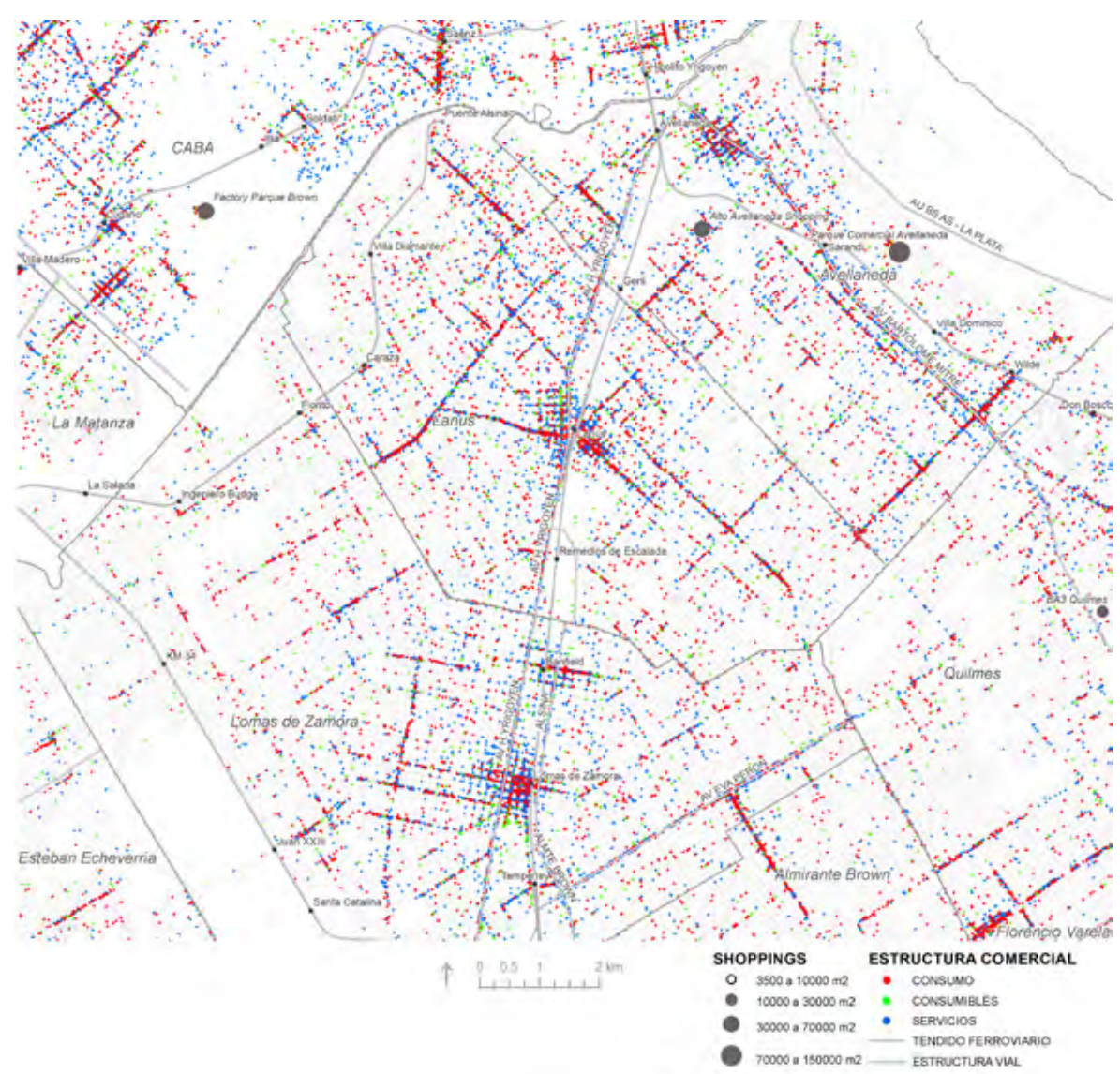

Figura 7. Estructura comercial en los municipios del sur de la RMBA. Fuente: elaboración propia.

El tejido urbano de este sector se caracteriza por su continuidad, sin vacíos intersticiales, y mezcla de usos, con convivencia de viviendas, galpones, talleres, pequeño comercio y servicios de proximidad, incluso en una misma manzana. Las centralidades tradicionales se vinculan a las estaciones ferroviarias y antiguas avenidas (H. Yrigoyen y Alsina-Almirante Brown, Av. Mitre-Av. Calchaquí, Av. Eva Perón) con escasa presencia de shopping centers. ${ }^{16}$ Existen numerosas centralidades lineales de escala barrial, configuradas por una o dos calles donde se localiza el comercio popular. En las últimas décadas, la revitalización del comercio de calle, junto a la densificación y verticalización del tejido residencial, constituyen las principales variables de reestructuración de las áreas centrales tradicionales.

A diferencia de la marcada estructura lineal del comercio en el eje norte y de su capilar infiltración en las tramas del eje sur, en el eje oeste la actividad comercial aparece mayoritariamente concentrada en los entornos de las estaciones ferroviarias (Ramos Mejía, Haedo, Morón, Castelar, Ituzaingó), alternándose con edificios en altura, equipamientos y servicios (Figura 8). 
Las configuraciones emergentes del consumo. Transformaciones del...

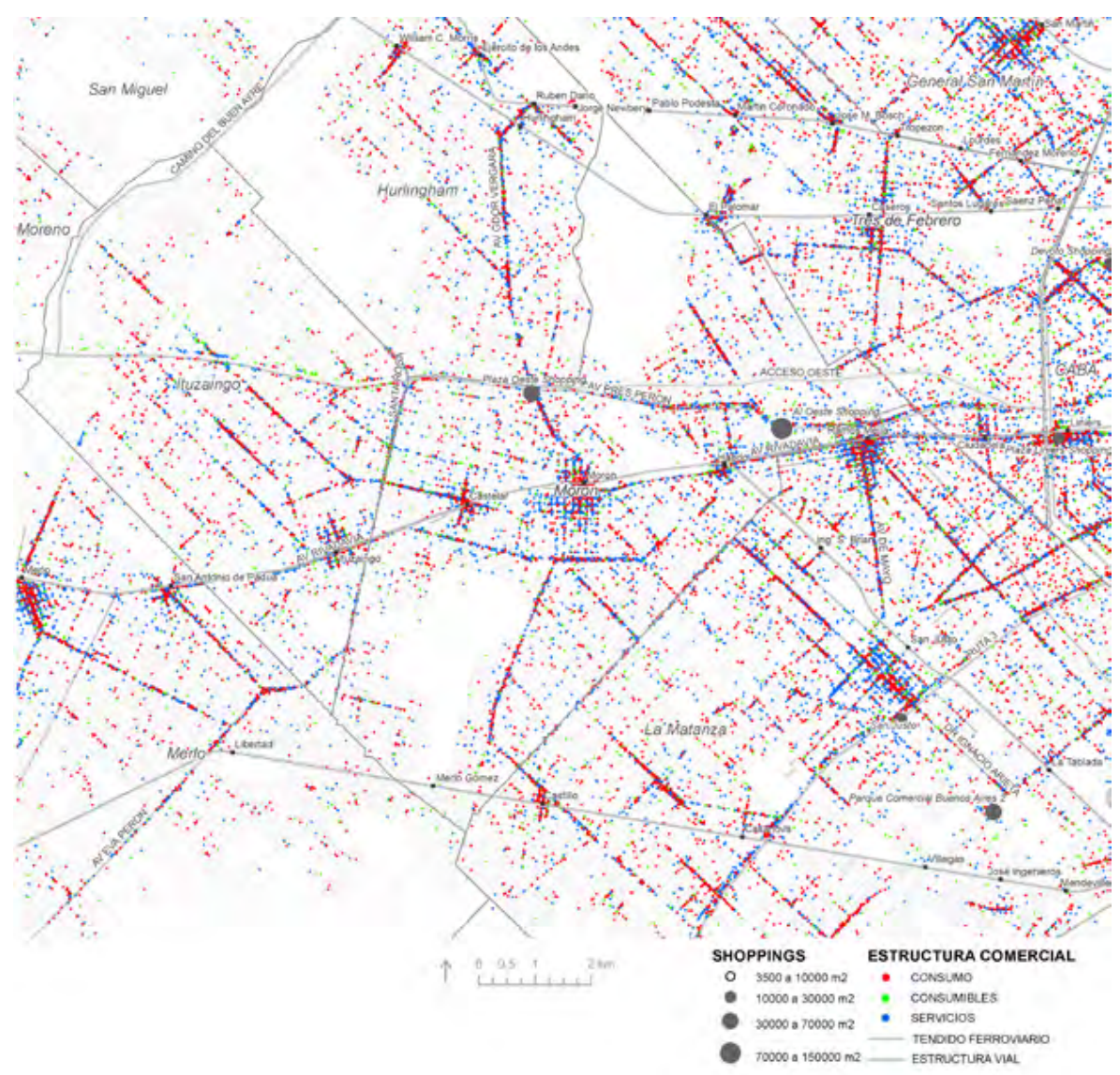

Figura 8. Estructura comercial en los municipios del oeste de la RMBA. Fuente: elaboración propia.

De manera complementaria, se desarrolla sobre el eje de algunas rutas o avenidas (ruta 7-Av. Rivadavia, Av. Presidente Perón, ruta 4-Av. Gobernador Vergara, ruta 3, Av. de Mayo, Santa Rosa, entre otras). Destaca la presencia de shoppings de gran tamaño como Al Oeste y Plaza Oeste. En el caso particular de San Justo, localidad cabecera del partido de La Matanza, el sector comercial se estructura en torno a la Av. Ignacio Arieta, peatonalizada en el tramo central, con un shopping muy próximo inaugurado en 2009.

\section{Nuevos o renovados productos comerciales}

\section{El aspecto tipológico de las transformaciones}

Una mirada nostálgica del comercio de calle, vinculado a la ciudad compacta y contrapuesto al arquetipo del shopping center como espacio comercial cerrado, rodeado de estacionamientos, socialmente homogéneo y ubicado en el suburbio (Salcedo y De Simone, 2013:126), soslaya la diversidad de configuraciones comerciales existentes en la RMBA que superan ampliamente estas dos tipologías.

Con base al relevamiento realizado y partiendo de los criterios morfológicos -no así de los de jerarquía- utilizados por Berry para la clasificación del comercio intraurbano 
Las configuraciones emergentes del consumo. Transformaciones del... LORENA VECSLIR, FLORENCIA SCIUTTO

(volver a la Figura 2), identificamos una serie de configuraciones comerciales que ordenamos en función de su patrón de asentamiento: nuclear, lineal, puntual y disperso (Figura 9).

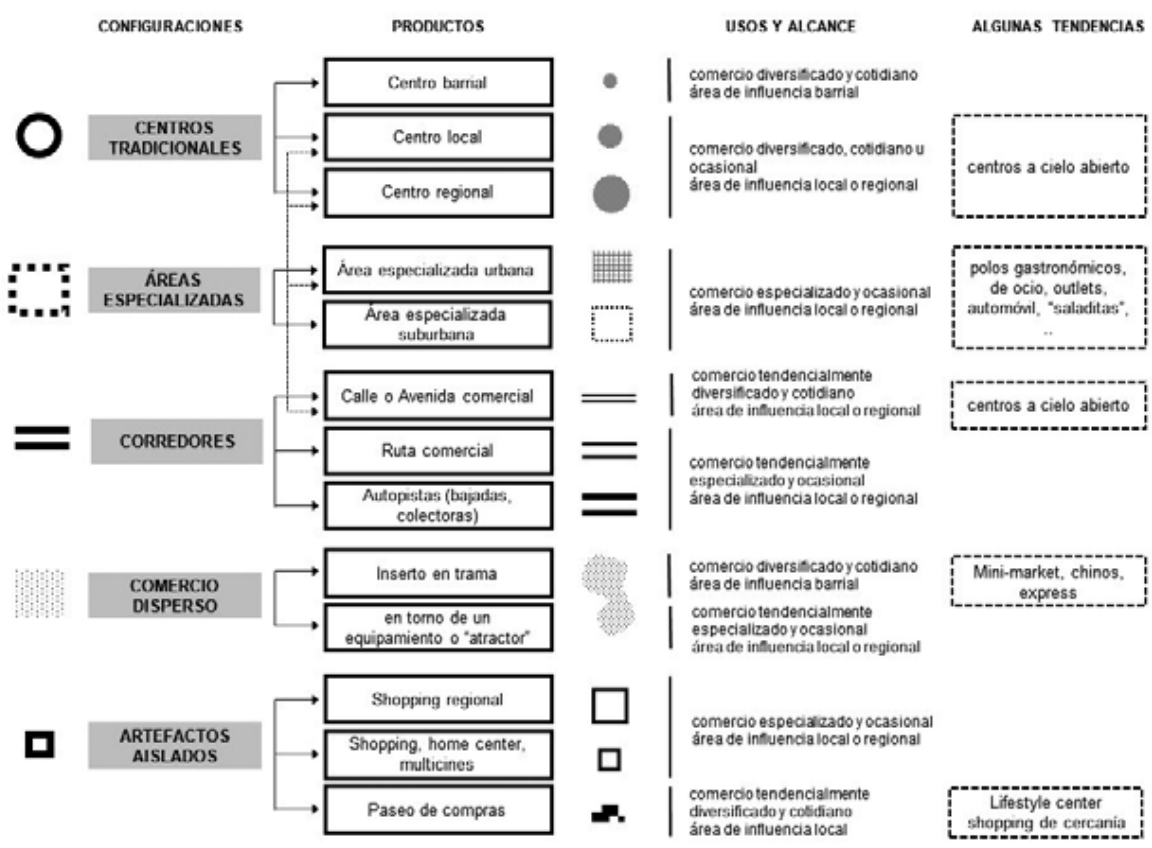

Figura 9. Configuraciones comerciales en la RMBA. Fuente: elaboración propia.

Así, encontramos situaciones en las que los comercios se agrupan, junto a otras actividades administrativas, de equipamiento y servicio, en las áreas centrales tradicionales. Aunque pueden surgir calles e incluso sectores con algún tipo de especialización, en general se trata de un comercio diversificado de uso más cotidiano u ocasional, dependiendo del tamaño y alcance del centro (barrial, local, regional). A nivel de la RMBA, dicha jerarquía no se da en forma escalonada, sino que se manifiesta en términos de distancia entre lugares de órdenes distintos, existiendo cientos de "microcentralidades" 17 integradas a la ciudad consolidada, con áreas de influencia que gozan de cierta autonomía respecto de las cabeceras municipales y de la CABA. Los bordes de estas centralidades no son simétricos ni regulares, sino que aparecen distorsionados por la presencia de barreras urbanas, grandes equipamientos, vías comerciales supramunicipales, infiltración de locales en tejidos residenciales, etc., generando límites difusos y situaciones de concatenamiento con otros sectores comerciales.

Un segundo tipo de asentamiento nuclear es el de las áreas especializadas (clústeres), las cuales se caracterizan por la presencia de locales del mismo rubro (gastronomía, ocio, muebles, automóvil, outlets de indumentaria, etc.). Sin embargo, existen dos tipos muy distintos de áreas especializadas según se ubiquen en la ciudad compacta, transformando sectores de tejido urbano existente, o en la periferia ocupando vacíos territoriales en áreas de baja densidad. En el primer caso, se trata de configuraciones 
Las configuraciones emergentes del consumo. Transformaciones del... LORENA VECSLIR, FLORENCIA SCIUTTO

abiertas que nacen a raíz de sustituciones o renovaciones tipológicas, parcela a parcela (de vivienda o depósito a local comercial o de servicios), a veces en contigüidad a la centralidad tradicional. El segundo tipo se corresponde con un formato de recinto cerrado, "ambientado" y con locales construidos ad hoc. En general, tienen un alcance superior al del barrio o localidad donde se insertan y suelen orientarse a un segmento socioeconómico determinado, cuyo poder adquisitivo es independiente de la localización urbana o suburbana del clúster. Incluimos en esta categoría las ferias o concentraciones de comercio informal (tipo "saladitas") con gran relevancia en algunos sectores de la RMBA. ${ }^{18}$

Los corredores o desarrollos lineales se extienden dentro y fuera de la ciudad compacta. El tipo de comercios suele ser diversificado en los tejidos centrales y tendencialmente especializado (mueblerías, concesionarios, corralones) hacia las periferias de los mismos. Sin embargo, dentro de las centralidades tradicionales pueden existir calles o avenidas donde predomine algún segmento comercial (electrónica, restaurantes, decoración, etc.); así como en los espacios de bajada y vías colectoras de la autopista, o en las calles laterales a los shoppings, observamos el surgimiento de comercios y servicios diversos (gimnasios, agencias de viajes, alquiler de autos y remises, outlets de indumentaria, etc.). El tipo de infraestructura (calle, avenida, ruta, autopista) de alguna manera "selecciona" los rubros y su alcance o área de influencia.

Respecto a las configuraciones puntuales, los artefactos comerciales aislados, podríamos hablar de una "evolución" de la caja cerrada o big box del shopping regional, al formato de paseo de compras -shopping village u open mall-, y de éste al shopping de cercanía o lifestyle center. Como se ha mencionado, su localización puede ser central o periférica y los comercios allí alojados incluyen desde franquicias hasta servicios cotidianos (tintorería, cerrajería, cajero, etc.). Los home centers, multicines e hipermercados también se consideran configuraciones comerciales puntuales. A diferencia de aquellos argumentos que postulan la hermeticidad de estos formatos, se corrobora en muchos casos su papel de "locomotora" o atractor de la actividad empresarial (oficinas, edificios corporativos), de grandes equipamientos privados (universidades, clubes deportivos, centros de salud) e incluso de nuevas formas de alojamiento temporal (hotel corporativo, suites, home \& office).

La dispersión de locales de comercio y servicio en las mallas residenciales existentes termina de completar el repertorio de cúmulos de actividad, en este caso de alcance más barrial, pero no necesariamente circunscriptos a la población del partido en el que se implantan mostrando, junto a los anteriores patrones de localización, dinámicas más complejas de relación intra e intermunicipal. El emplazamiento tiende a difundirse a lo largo de todo el tejido urbano, con preferencia de las esquinas de calles como puntos de enclave. Los entornos de otros grandes artefactos no comerciales, como centros médicos, universidades privadas y equipamientos deportivos, también aglutinan pequeño comercio con tipologías más o menos innovadoras. 
Las configuraciones emergentes del consumo. Transformaciones del... LORENA VECSLIR, FLORENCIA SCIUTTO

Sin pretender ilustrar un "modelo" de la estructura comercial de la RMBA, el esquema de la Figura 10 busca ejemplificar cómo se combinan, superponen y relacionan algunos de los componentes mencionados con el contexto de implantación y, especialmente, cómo se diversifican los formatos superándose los modelos jerárquicos escalonados.

Algunas de las causas de esta alteración radican en que no toda la oferta comercial y de servicios basa su lógica en criterios de proximidad. La captación del flujo de potenciales consumidores que utiliza las carreteras, grandes avenidas o, en general, los corredores urbanos de circulación no tiene relación con el ordenamiento jerárquico por áreas de mercado. Así como tampoco obedecen a ese criterio las áreas especializadas o los comercios que aprovechan las sinergias con un uso direccional (shopping, equipamiento, complejo corporativo) o con otras actividades del mismo rubro. Por tanto, a determinadas escalas, los patrones o lógicas de asentamiento del comercio minorista parecen responder más a estrategias de mercado y comportamiento de los usuarios que a jerarquías christallerianas, los cuales además pueden variar en el tiempo como producto de cambios sociales y de consumo.

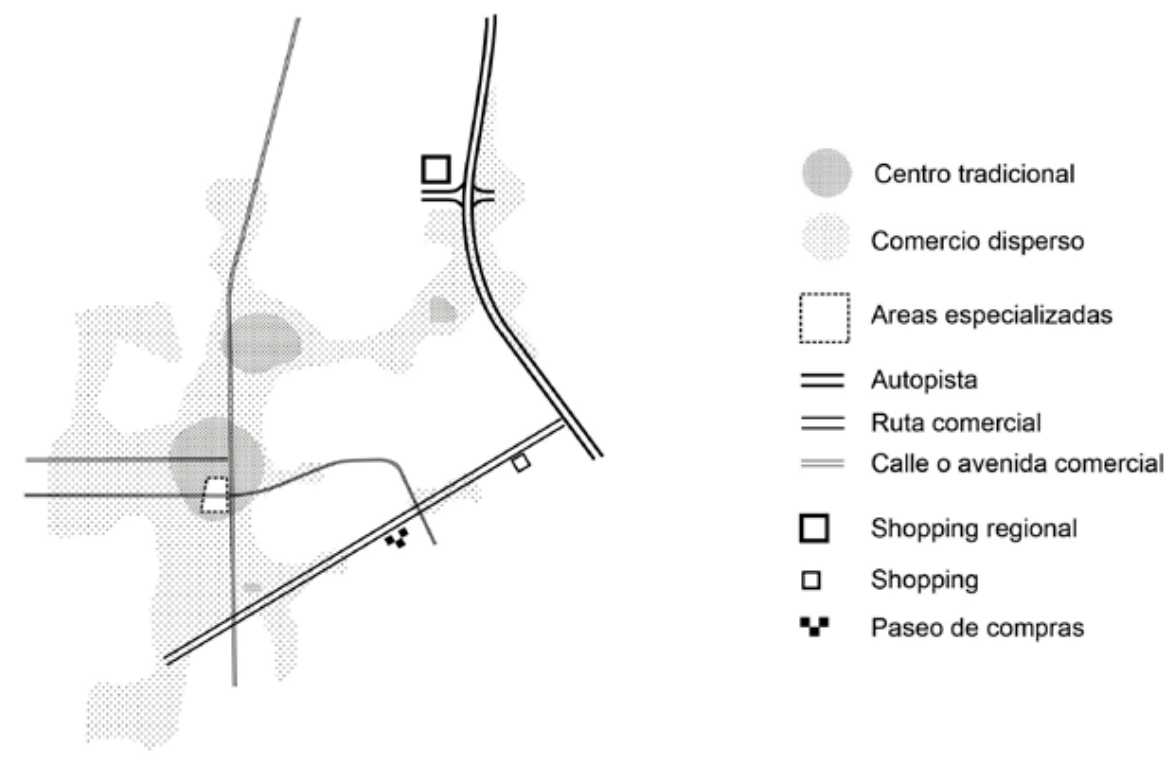

Figura 10. Esquema de estructuración de las tipologías del comercio minorista en un sector de la RMBA. Fuente: elaboración propia.

\section{Shoppings de cercanía, polos gastronómicos y centros comerciales a cielo abierto}

La aproximación a una categorización tipológica del comercio minorista para el caso de la RMBA nos permitió detectar algunas transformaciones recientes de carácter recurrente que, con base al relevamiento de notas periodísticas y trabajo de campo, pudimos indagar con mayor profundidad. Se trata de nuevos o renovados productos comerciales tales como shoppings de cercanía, polos gastronómicos y de diseño, y operaciones de renovación de centros tradicionales, que se superponen a la estructura comercial existente (Figura 11). 
Las configuraciones emergentes del consumo. Transformaciones del... LORENA VECSLIR, FLORENCIA SCIUTTO

Las crecientes inauguraciones de los denominados shoppings de cercanía o lifestyle centers, dan cuenta de la proliferación de un formato de pequeña dimensión que surge en respuesta a la demanda de productos y servicios cotidianos, proveniente de la población asentada en urbanizaciones cerradas. ${ }^{19}$ Este tipo de emprendimientos se ubica a una distancia promedio de $30 \mathrm{~km}$ desde el centro de la CABA, con predominio en el eje norte, especialmente a lo largo del corredor Bancalari-Benavidez y Av. Nordelta en el municipio de Tigre, y casos aislados en la zona sur, como en la localidad de Canning, la ruta 3 y la autopista Buenos Aires-La Plata.

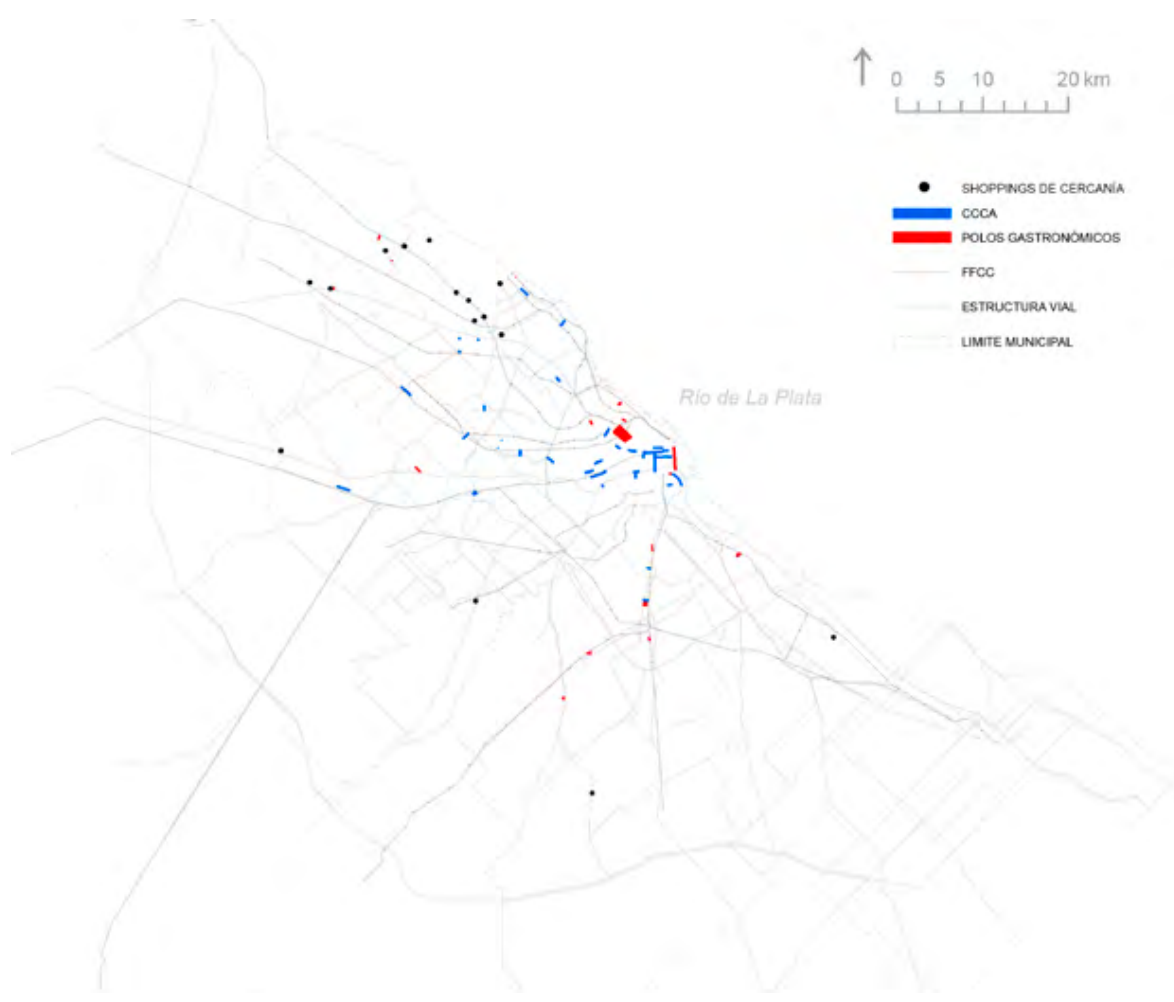

Figura 11. Shoppings de cercanía, polos gastronómicos y centros comerciales a cielo abierto. Fuente: elaboración propia.

Así como en los primeros countries de la RMBA existían las proveedurías y quioscos próximos al club house, el objetivo del shopping de cercanía es aportar -de manera más completa y sofisticada- espacios comerciales y de encuentro para los consumidores de las antiguas y nuevas urbanizaciones cerradas. Según referentes del mercado inmobiliario "en vez de pedir que la gente se acerque, son (los centros comerciales) los que se acercan a la gente" para atender la demanda de poblaciones que por su estilo de vida y consumo prefieren no trasladarse a la hora de realizar sus actividades cotidianas. ${ }^{20}$

De esta manera, los desarrollos están compuestos por un programa mixto que incluye, además de los locales comerciales, consultorios externos de distintas

19 Se relevó el desarrollo de quince shoppings entre 3.500 y $10.000 \mathrm{~m}^{2}$ desde el 2006 a la actualidad.

20 Recuperado de: https://www.lanacion.com.ar/economia/los-shoppings-de-proximidad-una-nueva-tendencia-de-consumo-que-se-impone-nid1331529 
Las configuraciones emergentes del consumo. Transformaciones del... LORENA VECSLIR, FLORENCIA SCIUTTO

especialidades médicas, oficinas y despachos profesionales e incluso, en algunos casos, vivienda. La imagen del centro comercial busca recrear un espacio de pequeña escala "en contacto con la naturaleza", con edificaciones dos o tres plantas de altura, intercaladas por espacios abiertos (plazas, anfiteatros, áreas de juegos para niños) y recorridos peatonales (Figura 12).

En lo que se refiere específicamente a las actividades comerciales se distinguen: aquellas de abasteimiento y servicio cotidiano (supermercado, cajero, farmacia, cafetería, heladería, pet-shop, librería, peluquería, gimnasio); los locales de diseño o con una oferta diferencial (vinoteca, deli, sushi, dietética, uniformes escolares, juguetería); así como las franquicias, especialmente de indumentaria, que compensan la menor afluencia de público con el mayor poder adquisitivo de los clientes.
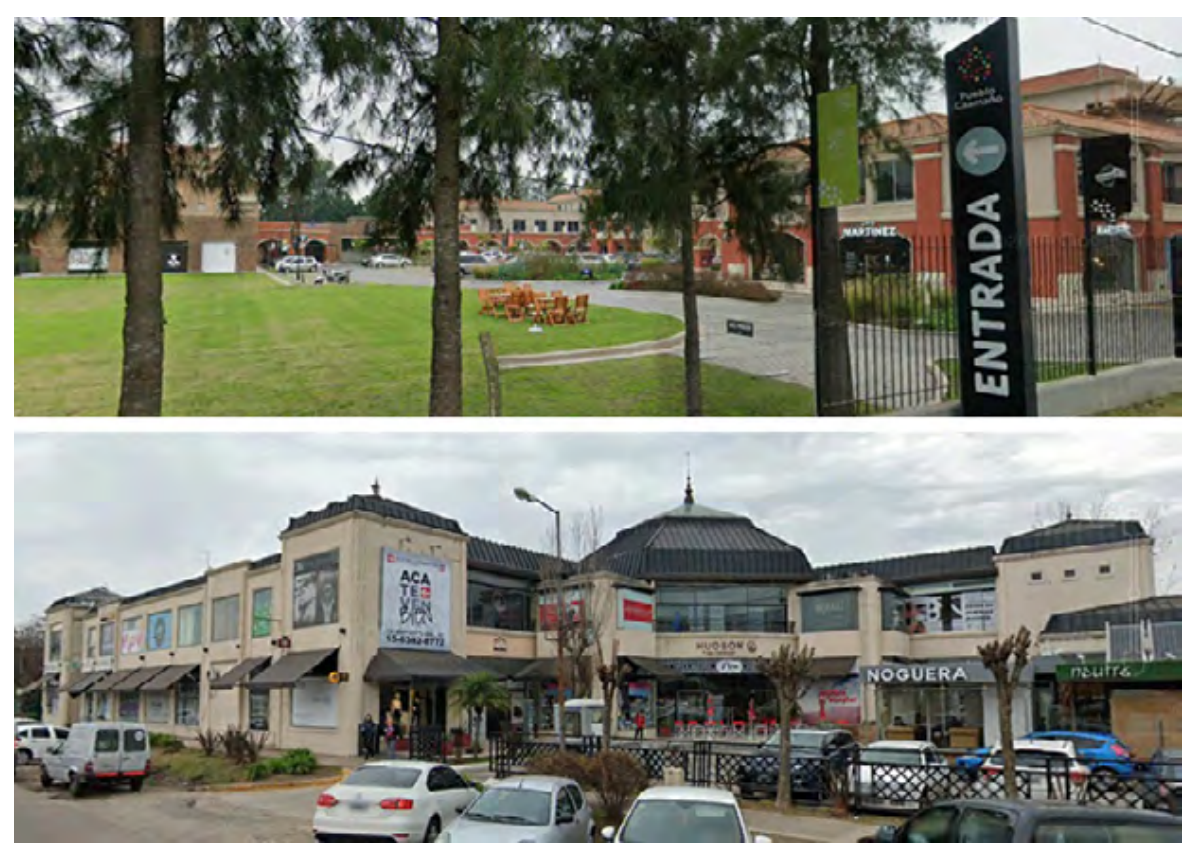

Figura 12. Shoppings de cercanía. Pueblo Caamaño (Pilar) Hudson Plaza Comercial (Berazategui). Fuente: Google Street View.

Paralelamente al shopping de cercanía, se registra el surgimiento de nuevos polos gastronómicos y de diseño, en diversas localidades de la RMBA. ${ }^{21}$

En la CABA, las cantinas, bodegones, bares, cafés, restaurantes, pizzerías o parrillas de Palermo Viejo y Palermo Hollywood, Las Cañitas, Av. Caseros, Doho, entre otros, se han ido sumando a los tradicionales polos gastronómicos de Recoleta, Puerto Madero y San Telmo. De manera conjunta, la promoción y puesta en valor de nuevos espacios y mercados, las ferias y concursos de comida, son algunas de las iniciativas del gobierno local orientadas a diversificar las zonas donde vivir distintas experiencias gastronómicas. ${ }^{22}$ Una actividad que ha pasado de actuar como subsidiaria de otros

21 Se relevaron dieciocho polos gastronómicos, siete en CABA y el resto en la RMBA.

22 Recuperado de: https://soloporgusto.com/ba-capital-gastronomica/ 
Las configuraciones emergentes del consumo. Transformaciones del... LORENA VECSLIR, FLORENCIA SCIUTTO

atractores a constituir ella misma un motivo de viaje y/o experiencia turística, con frecuencia capitalizada por las políticas públicas locales como recurso económico (Rodríguez, 2018).

Pero estas transformaciones no se limitan a la CABA. En la zona norte de la RMBA existen casos como la calle Mendoza y el Mercado eco-friendly de Ingeniero Maschwitz (Escobar), el boulevard Saenz Peña y la feria Sabe La Tierra en Tigre o la Av. Libertador en Punta Chica (San Fernando) que atraen usuarios de los propios partidos y partidos vecinos, pero también, durante el fin de semana, público proveniente de la CABA. En estos enclaves se combina una oferta gastronómica gourmet (hamburguesas de autor, patios cerveceros, cafés de especialidad, locales de delicatessen, heladerías artesanales, restós de comida étnica), con locales de indumentaria de diseñadores independientes, casas de decoración, anticuarios, talleres de artistas plásticos y shows al aire libre. Algunos casos, como el Mercado de Maschwitz o La Aldea en Pilar, han recreado una ambientación estilo vintage mediante el reciclaje de containers, el uso de materiales de demolición, chapas acanaladas, maderas patinadas, empedrados, herrajes y cerramientos antiguos.

La Av. Martin Fierro en Parque Leloir da cuenta de una tendencia que comienza a extenderse también hacia el oeste de la región, orientada especialmente a los residentes de countries y barrios cerrados, así como al creciente desarrollo de complejos de oficinas.

En la zona sur el desarrollo de polos gastronómicos adquiere algunas características particulares, situándose en contigüidad a los centros tradicionales como "extensión selectiva" de los mismos y abasteciendo a una cuenca de población que va más allá de las localidades de pertenencia. Destacan los sectores apodados "Las Lomitas", adyacente al centro de Lomas de Zamora, "La Lanusita", emplazado en torno de la calle Del Valle Iberlucea en el partido de Lanús, "Viejo Adrogué" en la calle Cordero de la localidad homónima, y "Paseo Dorrego" en Monte Grande. El proceso de desarrollo de polos gastronómicos ha significado en estos casos la transformación de antiguos sectores residenciales mediante el reciclaje de casas unifamiliares para alojar los nuevos restaurantes, bares y locales comerciales, así como la progresiva verticalización a partir del surgimiento de nuevas tipologías de vivienda en altura (Figura 13).

Un estudio específico de los patrones de movilidad cotidiana en algunas centralidades del eje sur realizado recientemente (Vecslir et al., 2018) confirmó la capacidad de atracción que estas áreas tienen por fuera de los propios municipios, con una movilidad dominante "desde la periferia hacia el centro", a la inversa de lo que sucede en el eje norte con los centros comerciales y/o corporativos de localización suburbana próximos a enlaces de autopistas, que atraen viajes "desde el centro hacia la periferia". 
Las configuraciones emergentes del consumo. Transformaciones del... LORENA VECSLIR, FLORENCIA SCIUTTO
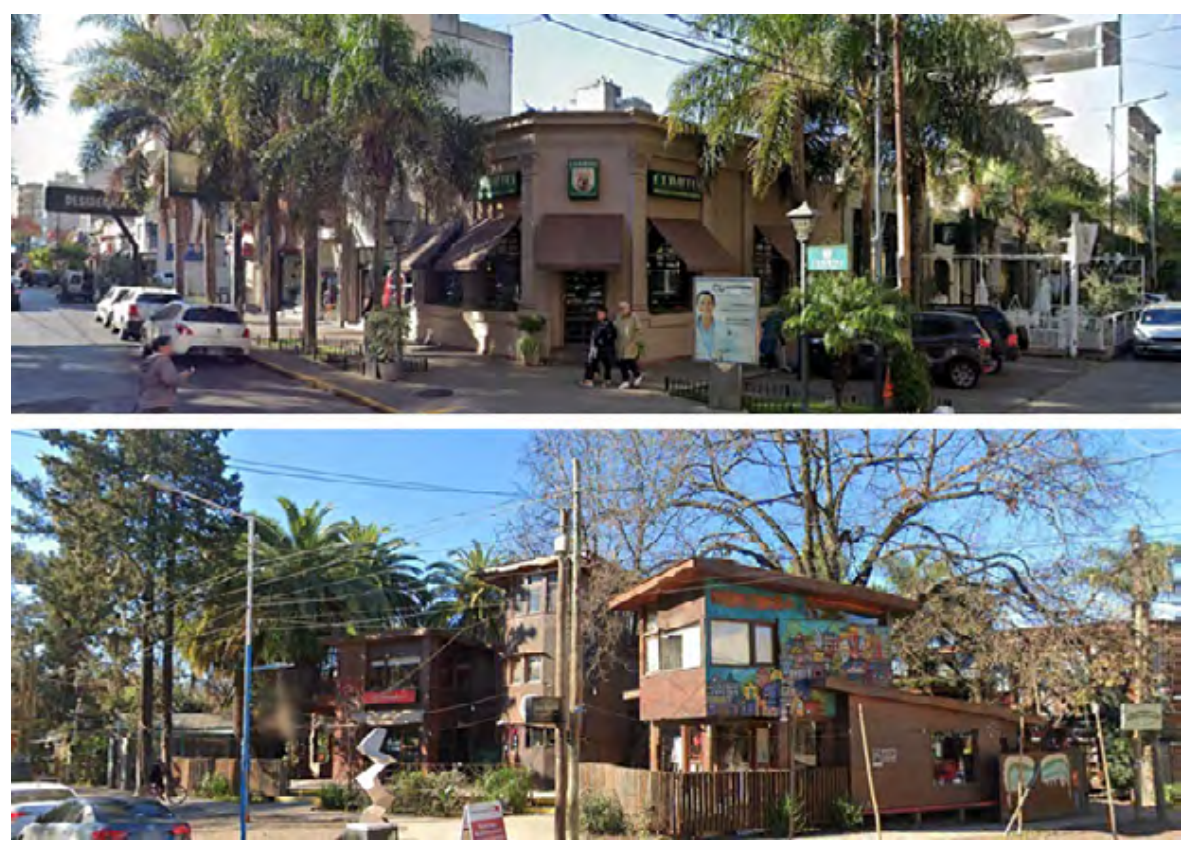

Figura 13. Polos gastronómicos. Calle España (Las Lomitas, Lomas de Zamora) y calle Mendoza (Maschwitz, Escobar). Fuente: Google Street View.

Por último, interesa mencionar una tendencia de transformación del comercio minorista impulsada desde las políticas municipales. Se trata de los acuerdos formulados entre la Confederación Argentina de la Mediana Empresa (CAME) -que canalizó fondos BID a través del Programa PROCOM (Programa de fortalecimiento al comercio minorista)-y diversos municipios de la región para el desarrollo de Centros Comerciales a Cielo Abierto (CCCA).

La versión local del modelo español de $\mathrm{CCCA}^{23}$ ha poblado los subcentros tradicionales de la RMBA de calles renovadas sobre la misma imagen urbana. Con distinto grado de concreción existen 33 iniciativas de CCCA en la RMBA ${ }^{24}$ (Vecslir y Rodríguez, 2018) que se traducen en propuestas de urbanización del espacio público (peatonalización, cambios de solado, soterramiento del cableado eléctrico, nueva luminaria, códigos de cartelería), animación y promoción comercial (campañas de marketing, eventos culturales) (Figura 14).

La mayor parte de los CCCA ejecutados se despliegan sobre uno o dos de los ejes con más dinamismo comercial, próximos a las estaciones ferroviarias, en una extensión que varía de dos a diez cuadras. Los respectivos gobiernos municipales han sido los mayores responsables en la ejecución y el financiamiento de los proyectos, que involucraron las iniciativas antes mencionadas, en los cuales la CAME actuó como un asesor de la Municipalidad, las asociaciones de empresarios (cámaras de comercio e industria) y, eventualmente, otras organizaciones públicas y privadas (entes de turismo, colegios profesionales o entidades financieras).

23 En Argentina, con base en antecedentes españoles (por ejemplo, Málaga, Valencia, San Sebastián, Villaviciosa- Asturias, Bilbao, Vitoria y Pamplona), el CCCA es definido como un "conjunto de comercios y servicios que comparten una zona geográfica de la ciudad (distrito o eje urbano central, intermedio o periférico), que deciden ofrecer una imagen unitaria de calidad sustentable" (CAME, 2016:4).

24 Estas iniciativas involucran a los municipios de Morón, Lomas de Zamora, San Fernando, San Isidro, Tigre, Vicente López, Moreno, Hurlingham, Tres de Febrero, San Miguel, Pilar y Luján. 
Las configuraciones emergentes del consumo. Transformaciones del... LORENA VECSLIR, FLORENCIA SCIUTTO
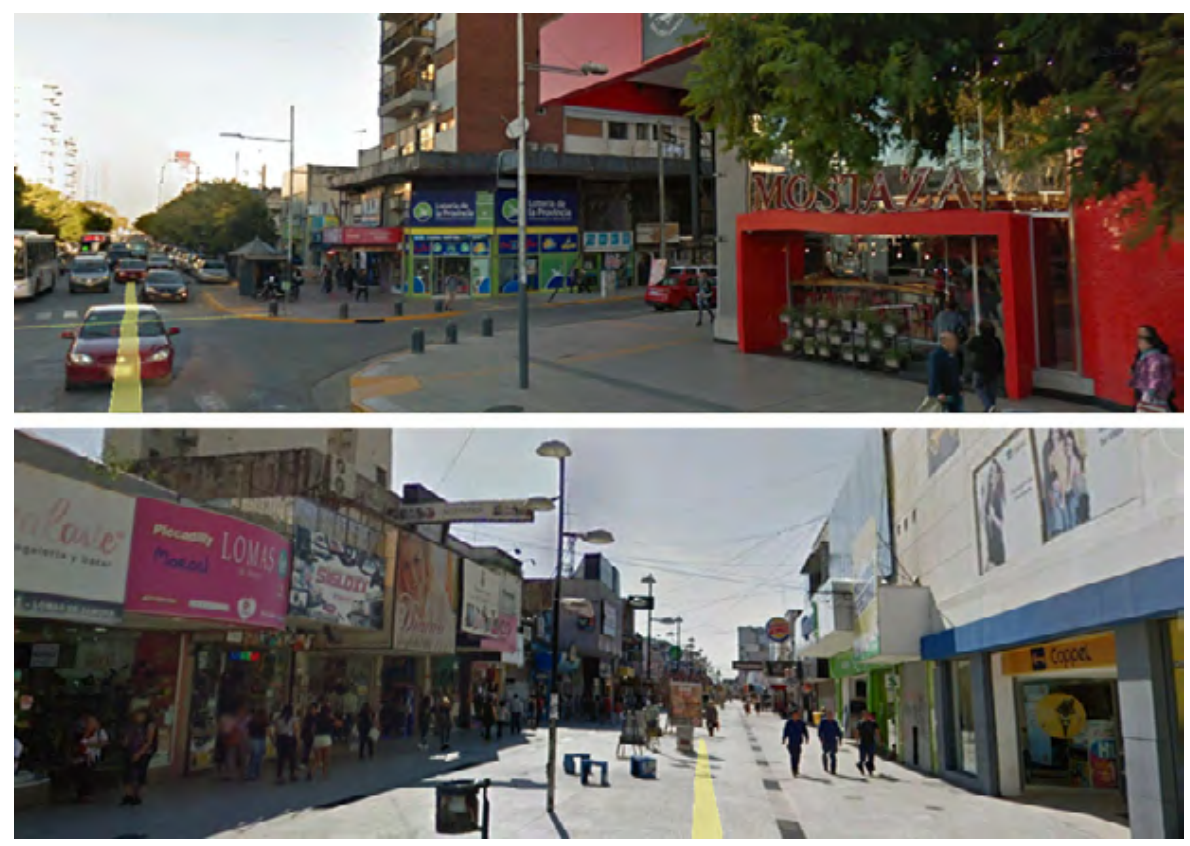

Figura 14. Centros comerciales a cielo abierto. Paseo San Miguel (San Miguel) y peatonal Laprida (Lomas de Zamora). Fuente: Google Street View.

\section{Notas de cierre}

A modo de cierre, cabe insistir en el protagonismo del comercio de calle que caracteriza a la RMBA frente a las modalidades del shopping center o del comercio on-line, sobre todo si la comparamos con otras grandes metrópolis latinoamericanas. Aunque es un aspecto que no se ha abordado en esta etapa de la investigación, destaca la resiliencia o capacidad de adaptación que han tenido las estructuras comerciales tradicionales a las crisis económicas, los cambios en las actividades productivas, las dinámicas inmobiliarias, los nuevos patrones de movilidad cotidiana e incluso a los protocolos y medidas de distanciamiento generadas en contexto de pandemia. Todos estos, procesos pocas veces planificados desde una visión integral.

Los argumentos anteriores, sin embargo, adquieren matices cuando analizamos las particularidades existentes en las diferentes zonas o corredores metropolitanos: con situaciones marcadamente urbanas, de concentración en torno de las estaciones ferroviarias o de hibridez y mixtura funcional de los tejidos, pasando por organizaciones más lineales que alternan comercio menudo y de grandes superficies, hasta contextos donde la vitalidad del comercio de calle -e incluso su pervivencia como imaginario de centralidad- ha quedado relegado frente a los nuevos artefactos del consumo.

En esta dirección, el artículo aporta elementos que contribuyen a explicar la superposición de nuevas lógicas a aquellas de la jerarquía por proximidad física o distancia a las áreas de mercado. Ciertos servicios, espacios de consumo y espacios "consumibles" responden a principios distintos, tales como el aprovechamiento de los corredores de circulación viaria o la complementariedad y competencia que establecen con otras actividades. Tampoco deben soslayarse las estrategias 
Las configuraciones emergentes del consumo. Transformaciones del... LORENA VECSLIR, FLORENCIA SCIUTTO

de localización basadas en cambios sociales o culturales, sobre todo en metrópolis donde la marcada polarización socioeconómica resulta determinante de la estructura comercial (Kunz, 2003:36).

En este marco, los datos provistos por Google Maps constituyen un insumo importante para la toma de decisiones. La cartografía de centros tradicionales según estándares de equipamiento y presencia de la actividad bancaria, contrapuesta al patrón de localización de los shopping centers, resulta de gran utilidad aunque no traduce la continuidad de la actividad comercial y de servicios en los corredores de alcance supramunicipal, característicos de la RMBA, y en la trama urbana en general, la cual sí es posible verificar con la construcción de mapas de grano más fino, como los elaborados en este trabajo.

El relevamiento de configuraciones comerciales puso en evidencia que la oposición tipológica "comercio de calle vs. shopping" unida a la oposición topológica "centro vs. periferia”, que ha caracterizado gran parte de la literatura disciplinar y de las políticas urbanísticas vinculadas, resulta insuficiente a la hora de entender la complejidad de los formatos presentes en la RMBA, los cuales además van sufriendo variaciones en el tiempo.

En este sentido, se observa una tendencia generalizada a configuraciones más "abiertas" de los formatos. La vitalidad de los corredores comerciales supramunicipales, las numerosas operaciones de centros comerciales a cielo abierto, así como la emergencia de ciertos distritos gastronómicos y de diseño adyacentes a los centros tradicionales, muestran la consolidación de patrones históricos de implantación del comercio minorista. Incluso los recientes formatos del shopping de cercanía o los polos gastronómicos de nueva implantación, directamente relacionados con las modalidades residenciales de baja densidad, buscan recrear configuraciones más cercanas al comercio de calle que al shopping cerrado (el big box característico de los años noventa).

Otro aspecto que deriva del análisis tipológico tiene que ver con el carácter de las transformaciones, las cuales no siempre implican total renovación. El relevamiento pone en evidencia la capacidad de hibridación del comercio con los usos residenciales e industriales de los tejidos existentes. A diferencia de otras metrópolis donde la emergencia o completa sustitución de las estructuras existentes por artefactos del ocio y el consumo caracteriza la oferta comercial como parte integrante de las "nuevas centralidades" metropolitanas, los sectores analizados muestran la combinación entre antiguos, nuevos y renovados formatos comerciales.

Por último, se destaca la potencialidad de estos análisis como insumo para la definición de políticas de planeamiento, actualmente enfocadas casi exclusivamente en intervenciones de CCCA. Más allá de estas iniciativas u otras propuestas limitadas al embellecimiento de la "imagen urbana" (peatonalizaciones, mejora del espacio público, regulación de cartelería, soterramiento de la red eléctrica) y regulación de las alturas de edificación en los centros tradicionales, las características funcionales y tipológicas recurrentes de las microcentralidades relevadas reclaman una consideración y tratamiento específicos por parte de los instrumentos de planeamiento y ordenación territorial.

Las políticas sobre el comercio minorista incluidas en los planes estratégicos o de desarrollo urbano municipales, en consonancia con las políticas de transporte, espacio 
Las configuraciones emergentes del consumo. Transformaciones del...

LORENA VECSLIR, FLORENCIA SCIUTTO

público y vivienda, deberían a su vez articularse con los programas provinciales o nacionales de mayor envergadura (rutas, transporte ferroviario, Metrobús, redes de servicios, vivienda social), superando los límites político administrativos que, como hemos visto, tienen poca relevancia en la estructuración del comercio en la RMBA.

Este trabajo fue realizado en el marco del Proyecto de Investigación Científico y Tecnológico (PICT) 2018-01361 "Centralidad, movilidad cotidiana y políticas públicas en el corredor noroeste de la RMBA", desarrollado en el Instituto de Geografía (Facultad de Filosofía y Letras, Universidad de Buenos Aires) y financiado por la Agencia Nacional de Promoción Científica y Tecnológica. Una versión preliminar del mismo fue presentada en el IV Congreso ISUF- $H$ (Barcelona, 28-30 septiembre 2020) con el título "Mas allá del shopping center: estructura y transformación del comercio minorista en la Región Metropolitana de Buenos Aires". 
Las configuraciones emergentes del consumo. Transformaciones del... LORENA VECSLIR, FLORENCIA SCIUTTO

\section{Q Bibliografía}

"Abba, A. (2005). Nuevas lógicas de centralidad urbana en el siglo XXI. Área Metropolitana de Buenos Aires. Centro de Investigaciones, Hábitat y Municipio (CIHaM), Documento de trabajo. Ciudad de Buenos Aires: FADU-UBA.

» Barata-Salgueiro, T. (2011). The resilience of urban retail areas. En T. Barata Salgueiro y $\mathrm{H}$. Cachinho (Eds.), Retail planning for the resilient city: Consumption and urban regeneration (pp. 19-44). Lisboa: CEG.

"Beavon, Keith (1981). Geografía de las actividades terciarias: una reinterpretación de la teoría de los lugares centrales. Barcelona: Oikos Tau. (Publicación original: 1977).

»Benach, N. (2000). Nuevos espacios de consumo y construcción de imagen de la ciudad en Barcelona. Estudios Geográficos, 61(238), 189-205.

" Berry, Brian (1971). Geografía de los centros de mercado y distribución al por menor. Barcelona: Vicens-Vives. (Publicación original: 1958).

»Bozzano, H. (2000). Territorios reales, territorios pensados, territorios posibles. Aportes para una Teoría Territorial del Ambiente. Buenos Aires: Espacio Editorial.

» CAME, Confederación Argentina de la Mediana Empresa (2016). Centros Comerciales Abiertos. 15 años. 100 ciudades. Revista Comerciar, Edición especial.

» Caprón, G. (1996). La ville privée: les shopping centers á Buenos Aires. Tesis Doctoral. Université de Toulouse II le Mirail, Francia.

"Carpio-Pinedo, J. (2014). Localización y evolución del comercio y servicios a pie de calle en los entornos urbanos. Factores locales frente a la multi-accesibilidad. El caso de la ciudad de Madrid. Territorios en Formación, 6, 63-84.

"Christaller, W. (1966). Central Places in Southern Germany. Englewood Cliffs, N.J.: Prentice Hall. (Publicación original: 1933).

»Ciccolella, P. (1999). Globalización y dualización en la región metropolitana de Buenos Aires. Grandes inversiones y reestructuración socioterritorial en los años noventa. Eure, 25(76), 5-27.

"Ciccolella, P. (2000). Distribución global y territorio. Modernización y concentración comercial en Argentina en los años noventa. Economía Sociedad y Territorio, 2(7), 459-496.

》 Ciccolella, P., Vecslir, L. y Baer, L. (2015). Revitalización de subcentros metropolitanos. Buenos Aires entre la ciudad dispersa y la ciudad compacta. Contexto, 11, 11-28.

„ CONAMBA, Comisión Nacional Área Metropolitana de Buenos Aires (1995). El Conurbano Bonaerense. Relevamiento y Análisis. Buenos Aires: Ministerio del Interior.

»Davies, R. (1972). Structural models of retail distribution. Analogies with settlement and urban land-use theories. Transactions of the Institute of British Geographers, 57, 59-82. 
Las configuraciones emergentes del consumo. Transformaciones del... LORENA VECSLIR, FLORENCIA SCIUTTO

»De Mattos, C. (2010). Globalización y metamorfosis metropolitana en América Latina. De la ciudad a lo urbano generalizado. Revista de Geografía Norte Grande, $47,81-104$.

"Dematteis, G. (1998). Suburbanización y periurbanización. Ciudades anglosajonas y ciudades latinas. En F. Monclús (Ed.), La ciudad dispersa (pp. 17-33). Barcelona: Centro de Cultura Contemporánea.

» DPOUyT, Dirección Provincial de Ordenamiento Urbano y Territorial (2007). Lineamientos Estratégicos para la Región Metropolitana de Buenos Aires. Provincia de Buenos Aires, Ministerio de Infraestructura, Subsecretaría de Urbanismo y Vivienda.

» García-López, M. y Muñiz Olivera, I. (2007) ¿Policentrismo o dispersión? Una aproximación desde la nueva economía urbana. Investigaciones Regionales, 11, 25-43.

»Gehl, J. y Svarre, B. (2013). How to study public life. Washington: Island Press.

»Gutman, G. (1997). Transformaciones recientes en la distribución de alimentos en la Argentina. Buenos Aires: Secretaría de Agricultura, Ganadería, Pesca y Alimentos (SAGPyA).

» Kunz, I. (Coord.) (2003). Usos del suelo y territorio. Tipos y lógicas de localización en la Ciudad de México. Ciudad de México: Universidad Nacional Autónoma de México - Plaza y Valdés.

» Limonta, G. y Paris, M. (2017). OSM come strumento di monitoraggio dei sistema commerciali urbani. Geoingegneria Ambientale e Mineraria, 54(2), 103-108.

» López de Lucio, R. y Parrilla Gorbea, E. (1998). Espacio público e implantación comercial en la ciudad de Madrid: calles vs grandes superficies. Cuadernos de Investigación Urbanística, 23. Madrid: Instituto Juan de Herrera, Universidad Politécnica de Madrid.

»Lösch, A (1957). Teoría económica espacial. Buenos Aires: El Ateneo, (Publicación original: 1939).

》Moreno Redón, S. (2011). Análisis teórico y aproximación práctica a las relaciones entre ciudad y comercio. El caso de la producción, venta y consumo de libros en Barcelona. Tesis doctoral. Universidad de Barcelona.

》 Rodríguez, L. (2018). Palermo Viejo: Palermo Soho. Los nuevos espacios de consumo como insumo del turismo urbano. En J. Mansilla y C. Milano (Coord.), Ciudad de Vacaciones. Conflictos urbanos en espacios turísticos, (pp. 289-326). Barcelona: OACU-Pol.len.

》 Ruiz Lineros, M. y Marmolejo Duarte, C. (2008). Hacia una metodología para la detección de subcentros comerciales: un análisis para Barcelona y su área metropolitana. ACE: Architecture, City and Environment, 3(8), 199-218.

"Salcedo, R. y De Simone, L. (2013). Una crítica estática para un espacio en constante renovación: El caso del mall en Chile. Atenea, 507, 117-132.

"Sevtsuk, A. (2010). Path and Place: A Study of Urban Geometry and Retail Activity in Cambridge and Somerville, MA. Tesis doctoral. Massachusetts Institute of Technology, Department of Urban Studies \& Planning.

" Truffello, R. e Hidalgo, R. (2015). Policentrismo en el Área Metropolitana de Santiago de Chile: reestructuración comercial, movilidad y tipificación de subcentros. EURE, 41(122), 49-74. 
Las configuraciones emergentes del consumo. Transformaciones del...

LORENA VECSLIR, FLORENCIA SCIUTTO

》Vecslir, L. y Rodríguez, L. (2018). Centros Comerciales a Cielo Abierto como política de renovación de las centralidades tradicionales en el Conurbano Bonaerense. Territorios, 38,15-40.

"Vecslir, L., Blanco, J., Nerome, M., Sciutto, F., Maestrojuan, P. y Rodríguez, L. (2018) Un corredor sin autopista. Centralidad y movilidad cotidiana en el sur de la región metropolitana de Buenos Aires. Ciudad de Buenos Aires: Café de las Ciudades Publicaciones FILO.

»Vecslir, L.; Ciccolella, P. (2011). Relocalización de las actividades terciarias y cambios en la centralidad en la Región Metropolitana de Buenos Aires. Revista de Geografía Norte Grande, 49, 63-78.

\section{Lorena Vecslir / lorena.vecslir@gmail.com}

Arquitecta (Universidad de Buenos Aires, UBA), Máster en Proyectación Urbanística y Doctora por la Universidad Politécnica de Cataluña. Investigadora independiente del Consejo Nacional de Investigaciones Científicas y Técnicas con sede en el Instituto de Geografía (IG, UBA). Profesora de grado en la Facultad de Arquitectura, Diseño y Urbanismo (UBA) y en la Universidad Nacional de San Martín; y de postgrado en diversas universidades nacionales. Investigadora responsable del PICT "Centralidad, movilidad cotidiana y políticas públicas en el corredor noroeste de la RMBA" (IG, UBA).

\section{Florencia Sciutto / florsci@gmail.com}

Arquitecta (Universidad de Buenos Aires, UBA), Maestranda en Economía Urbana (Universidad Torcuato Di Tella. Desde 2014 ha trabajado en diversos proyectos a escala urbana en la Corporación Antiguo Puerto Madero y colaborado en distintas consultorías municipales. Fue docente en las asignaturas Morfología Urbana y Arquitectura (UBA), Project Studio (Ryerson University, Canadá) y Taller de Urbanismo (Universidad Nacional de San Martín). Investigadora integrante del PICT "Centralidad, movilidad cotidiana y políticas públicas en el corredor noroeste de la RMBA" (IG, UBA). 